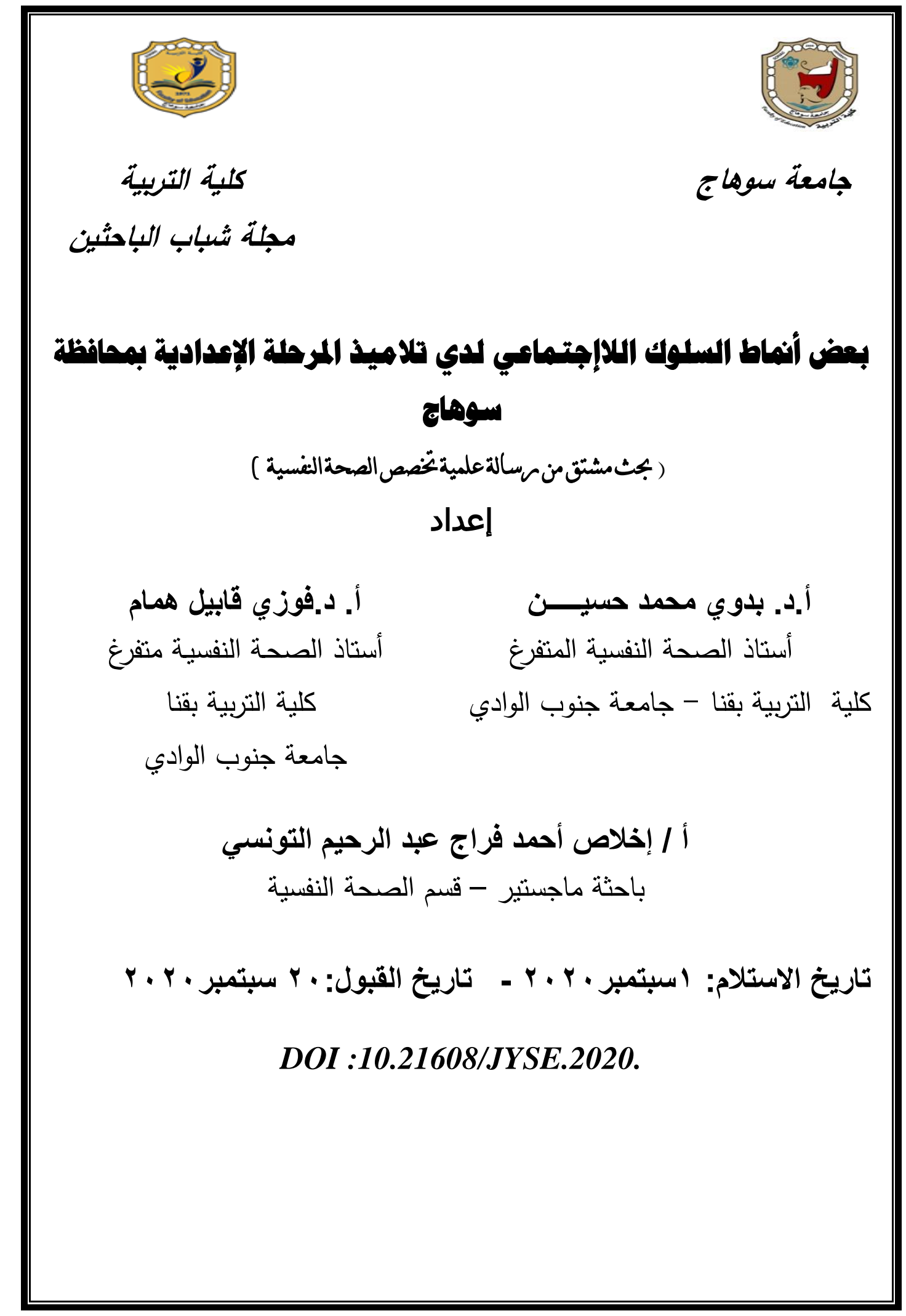




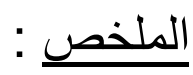

هافت الرسالة الحالية إلي التعرف علي فعالية برنامج إرشادي ديني في خفض بعض الرات

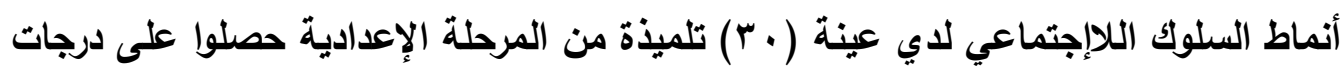
عالية على مقياس السلوك اللاإجتماعي وقسموا على مجموعتين ضابطة وتجريبية وتم تطبيق البرنامج الإرشادي الديني على المجموعة التجريبية وأظهرت نتائج الاراسة، وتوجد فروق ذابلة ذات دلالة إحصائية بين متوسط درجات تلاميذ المجموعة التجريبية في القياس القبلي ومتوسط التئي درجاتهن في القياس البعدي، علي مقياس أنماط السلوك اللاإجتماعي وأبعاده الفرعية (العزلة

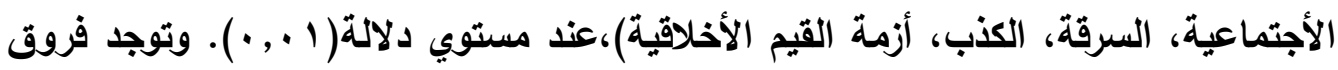

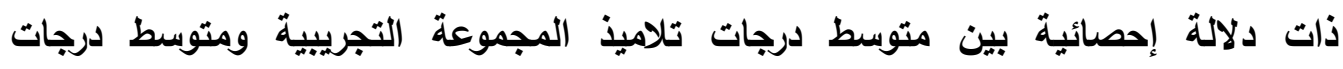
المجموعة الضابطة في القياس البعدي، علي مقياس أنماط السلوك اللاإجتماعي عند مستوي

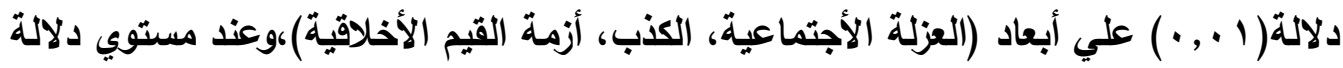

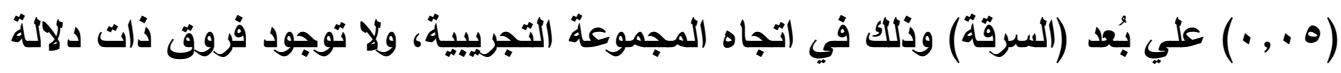
إحصائية بين متوسط درجات تلاميذ المجموعة التجريبية في القياس البعدي ومتوسط

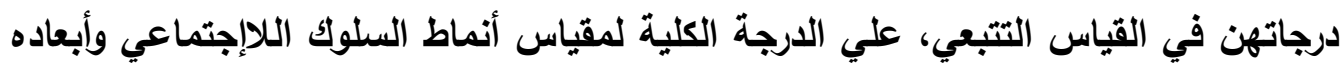

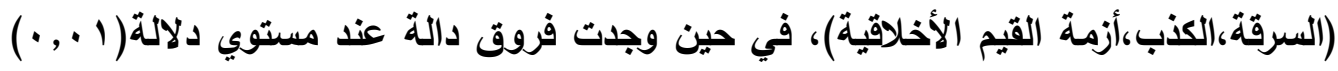

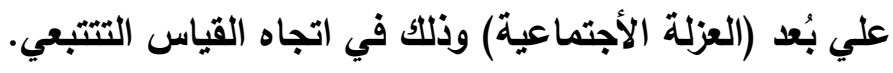

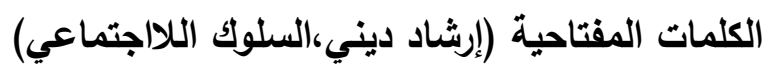




\section{Abstract of the stud}

The current message aimed to identify the effectiveness of a religious guidance program in reducing some types of socioeconomic behavior in a sample (30) students from the preparatory stage who received high scores on the scale of asocial behavior and divided into two groups of officers and pilots and the religious guidance program was applied to the group The results of the study showed, and there are statistically significant differences between the average grades of students of the experimental group in tribal measurement and their average score in dimensional measurement, on the scale of asocial behavior patterns and their sub-dimensions (social isolation, theft, lying, crisis of moral values) At a level of significance (01.0). There are statistically significant differences between the average grades of students of the experimental group and the average score of the control group in the dimension measurement, on the scale of the pattern sa'ad patterns at the level of indication (01.0) on dimensions (social isolation, lying, crisis of moral values), and at the level of indication (05.0) In the direction of the experimental group, there are no statistically significant differences between the average grades of students of the experimental group in the dimensional measurement and their average score in tracking measurement, on the overall score of the measure of antisocial behavior patterns and dimensions (theft, lying, crisis of moral values), in When i found significant differences at the level of indication (01.0) at the distance (social isolation) in the direction of the tracking measurement.

Keywords (religious guidance, social behavior) 


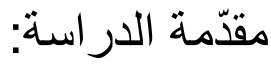

يعد السلوك اللاجتماعي Antisocial behavior ،موضوعاً محورياً علي مستوي كل من الفرد والمجتمع بل وعلي مستوي العالم ككل، فنحن في عصر يمكن تسميته بعصر السلوك اللاجتماعي والانحراف ،والصراع بين جيل تعود علي أساليب وعادات وأنماط سلوكية سوية راسخه مستمدة من الدين والمجتمع ، وجيل أخر لا يجد في هذه الأساليب والعادات

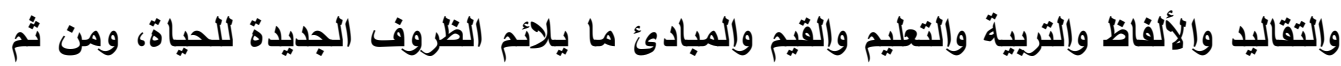
نجده يرغب في تغيرها والأخذ بالسلوكيات الجديدة في التغيير والتعامل مع الأخرين عاطفياً، لإليأ

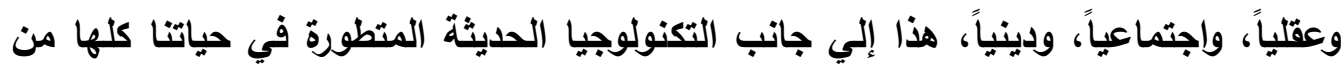
ملبس ومأكل وأجهزة ونوادي ومدارس وإمكانيات وتطورات كثيرة لا حصر لها، أدت بالبات بالإنسان

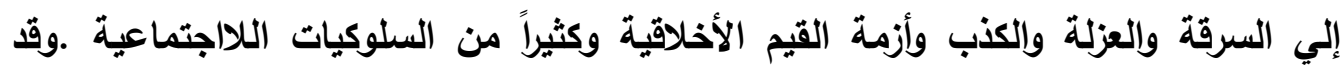

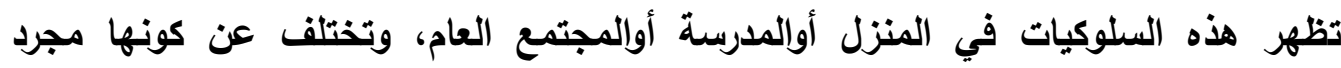

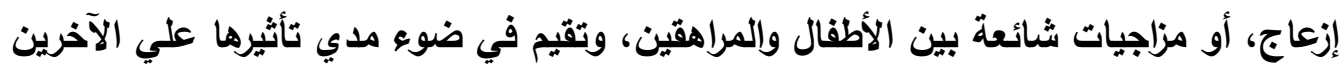

وممتلكاتهم وعلي الأعراف الاجتماعية (Outmans \& Emery, 1998, 575). وتعد مرحلة المراهقة من المراحل المهمة في عمر الإنسان فهي التي تظهر فيها التغيرات الفسيولوجية والسيكولوجية للمراهق فتحدث التغيرات في الثكل والمظهر والسلوكيات فيحاول

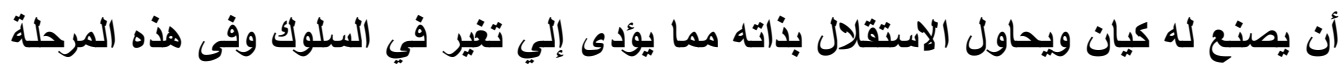
يشعر المراهت بتشتت في الأفكار إذا لم يجد من يحتويه ويحتوى أفكاره ويوجهه إلى السلوك - القويم

وأثار (Jamil,2007) إلى أن الدراسات أظهرت أن الأطفال الذى يظهرون سلوكاً

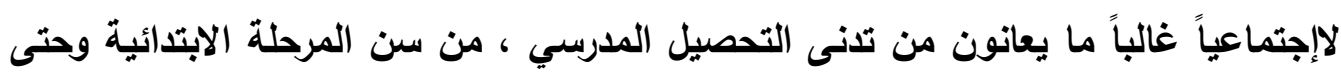

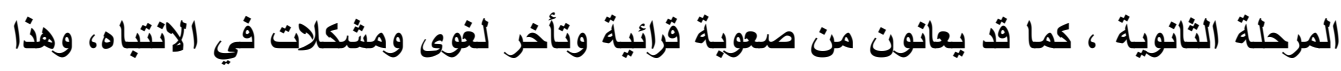
بدوره يزيد من احتمال تدنى تقدير الذات عند هؤلاء الأطفال، أما السلوك اللإجتماعى فينشأ

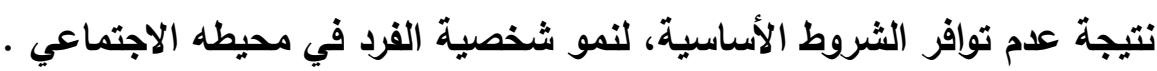

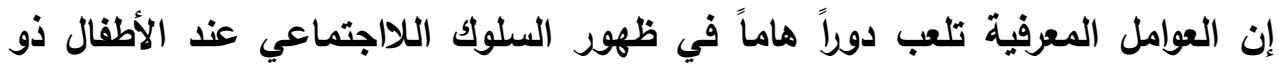

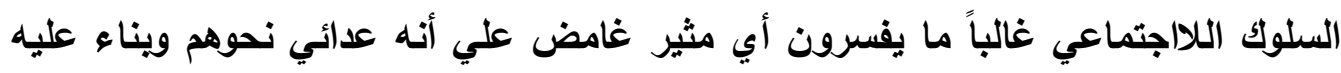

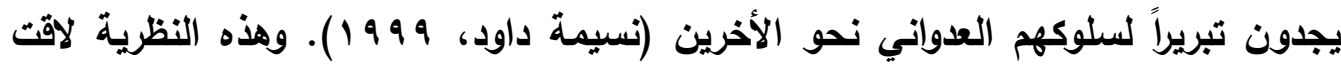


تأييا واسع من جانب الفقه الحديث الذي يفضل تسميتها بنظرية (الاستعداد اللاإجتماعى أو الانحرافي " ذلك أن هذه التسمية تعتبر أكثر شمولا من تعبير " الاستعداد "، ويسمح بتفسير الجريمة كواقعة قانونية متغيرة بحسب الزمان والمكان. لأ فإن البحث الحالي يعد محاولة من جانب الباحثة للتعرف على بعض بأن أنماط السلوك اللاإجتماعى لاى تلاميذ المرحلة الإعدادية.

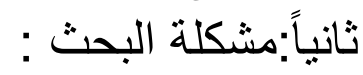
نبعت مشكلة البحث من خلال الإطلاع علي الدراسات السابقة التي تناولت السلوك اللاإجتماعي لدي تلاميذ المرحلة الإعدادية،والتي تؤكد معاناة اللآخرين من الإنس السلوكيات اللاإجتماعية التي تسبب الكثير من المشكلات العامة والخاصة وإنتشار السلوكيات

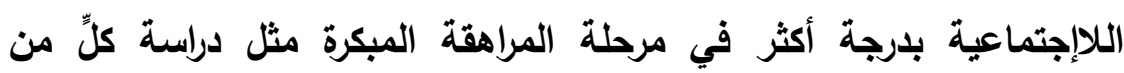

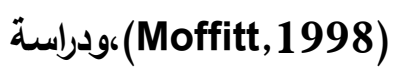
(Jamila,2007;Mayer,2001) (Wells\&Forhand,1985) المعلمات والمعلمين والأخصائي الاجتماعي والأخصائي النفسي ،تبين مدي معاناة هذه الفئة

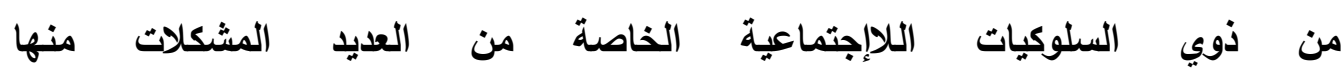

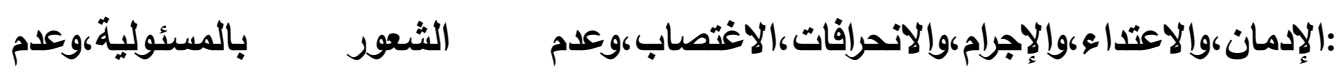

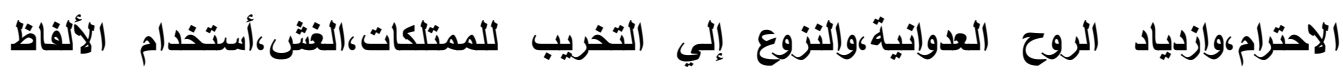

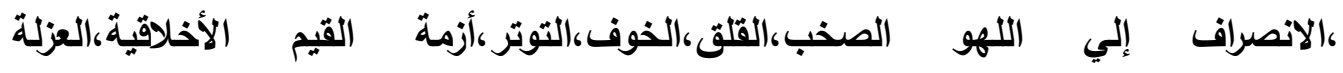
الاجتماعية،الكذب،السرقة وعدم القدرة علي مواجهة المشكلات السلوكية وإلتكيف معها ،ومدي حاجتهم للتخلص من هذه السلوكيات اللااجتماعية خاصة وأنهم في مرحلة المراهقة المبكرة .

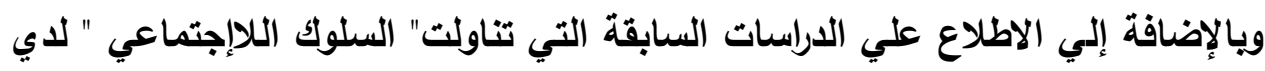
تلاميذ المرحلة الإعدادية اتضح قلة الدراسات - علي حدود علم الباحثة - التي تناولت هذا لإسيات

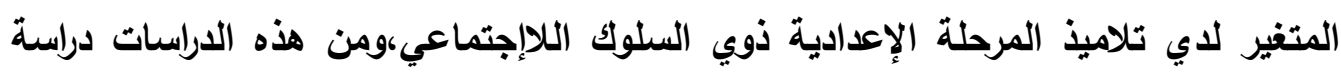
ماجد جبر، • 1 •r،والتي أكلت علي انخفاض السلوك اللاإجتماعي لاي تلاميذ المرحلة الإعدادية . ماجد، 
ويلاحظ بالرجوع للتراث البحثي في مجال السلوك اللاإجتماعي أنه أهتم بشكل كبير

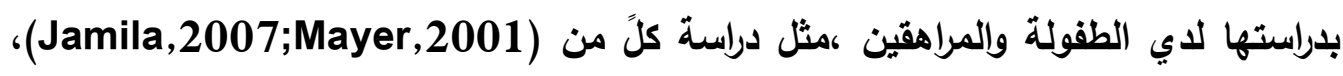

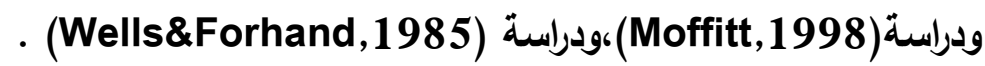
التسـاؤل الرئيس: " ما أنماط السلوك اللاإجتماعى الثائعة لـى الدى التلاميذ المرحلة الإعدادية؟؟ " ثنالثاً: أهداف أنماط البطوك: هدفت الدراسة الحالية إلى ما يلي: البح:

(1) الكشف عن بعض أنماط السلوك اللاإجتماعى لدى عينة من تلاميذ المرحلة الإعدادية.

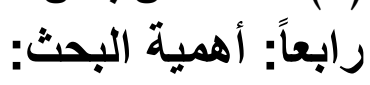
من العرض السابق يتضح لنا أن مشكلة السلوك اللااجتماعي بين تلاميذ المدارس تثكل

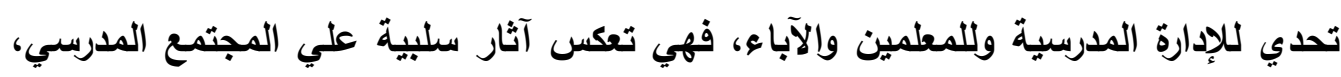

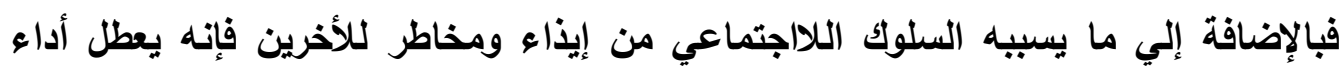
الأخرين وواجباتهم أو أعمالهم المدرسية، كما يعوق المعلم عن القيام بدوره التعليمي والتربوي، ويمتد تأثيره السلبي إلي عدم جود العلاقات الاجتماعية بينه ويين التلاميذ.

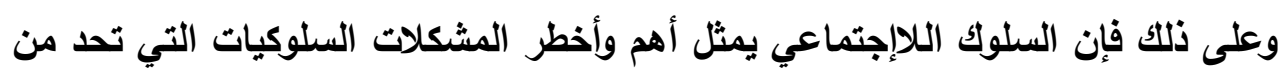
خفض وفاعلية البرامج التدريبية والتأهيلية، لذلك يحتاج الطلاب إلى معرفة ما يجب دلب عليهم

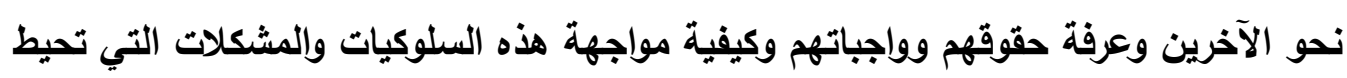
به ومعرفة كيفية التعامل مع الآخرين. ولذلك فإنه ينظر للسلوك اللااجتماعي علي أنه سلوك مضاد للمجتمع،حيث يعتبر سلوكاً

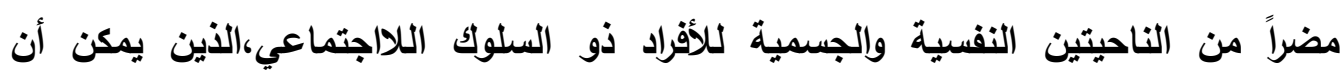
يستجيبوا للسلوك اللاجتماعي بطرق متعددة مثل:الفرار،أو التجنب،أو الاستلام، ولقد أمر الله

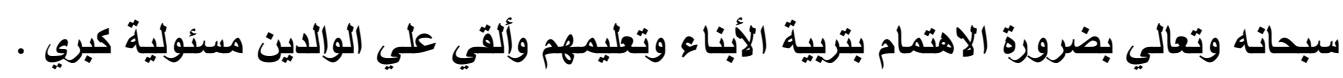

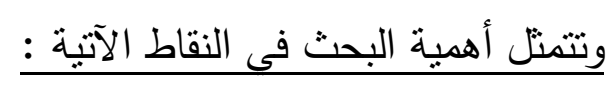
1- الاهتمام بطلبة المرحلة الإعدادية ومحاولة إعدادهم بشكل جيد يأبى من ضمن أولويات التعليم الناجح، كما يعد ضرورة علمية وحضارية من أجل الاستفادة من قدراتهم 
وتطويرها، بهدف المساعدة في تطوير وتعديل أو خفض السلوك اللااجتماعى، كما أن الاهتمام بهم أيضا يعد ضرورة تريوية.

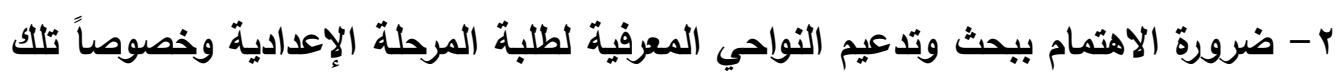
التي تؤثر بشكل مباشر وقوى على خفض بعض أنماط السلوك اللاإجتماعى لاى الطلاب. r- توضيح مفهوم السلوك اللاإجتماعى لدى العينة بما في ذلك أبعاده.

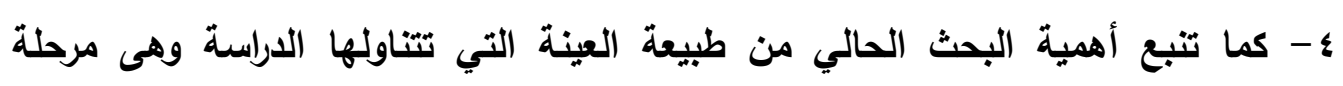
المراهقة التي هي مرحلة الإعداد للشباب وكنلك من طبيعة الموضوع الذى تتناوله وهو

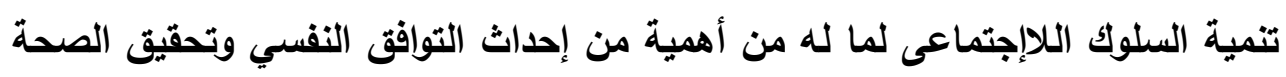
النفية مما ينعكس على شخصية الفرد ونجاحه في الحياة. خامساً:مصطلحات البحث: البهن:

السلوك اللاإجتماعي: Antisocial Behavior أنه مجموع الارجات التي تحصل عليها الطالب علي مقياس السلوك اللااجتماعي المستخدم في هذه الدراسة كدرجة كلية ويدرجات علي أبعاده الفرعية الأربعة وهي: (سرعة الغضب، والسلوك العدواني، والفوضوية، والتمرد

$$
\text { والعصيان) "عبد الله محمود محمد الزيتاوي" (7 } 17 \text { ب). }
$$

وتعرف إجرائياً بأنه : هو سلوك مزعج ويتنافي مع الأخلاقيات والقيم الدينية لكل من الفرد والمجتمع قد يكون نتيجة عوامل داخلية تتعلق ب ( نفسه،أسرته) وقد تكون نتيجة عوامل فئل

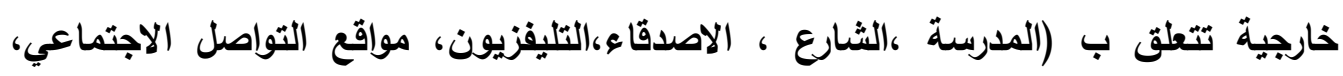

الإنترنت) وتؤثر فيه ويتأثر بها في النواحي العلمية والعملية .

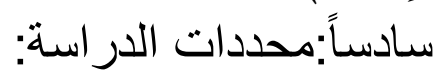
تحددت هذه الدراسة بعدد من المحددات تمثلت في :

$$
\text { محددات زمانية: }
$$

طبقت الدراسة في الفصل الدراسي الأول لعام 9 ـ ب م ، واستغرق التطبيق مدة شهرين .

$$
\text { محددات مكانية: }
$$

تم تطبيق المقياس المعد للاراسة الحالية علي بعض مدارس المرحلة الإعدادية التعليم العام

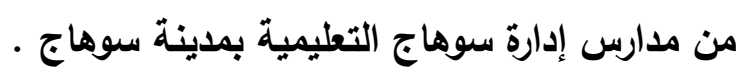


تكونت عينة الاراسة الأساسية من (• r ) تم التطبيق على مجموعة من تلاميذات المرحلة

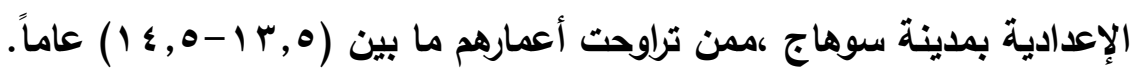

$$
\begin{aligned}
& \text { محددات إجرائية: } \\
& \text { أدوات الدراسة : } \\
& \text { تحددت الأدوات المستخدمة في هذه الدراسة فيما يلي : } \\
& \text { مقياس السلوك اللاإجتماعي • إعداد : الباحثة. } \\
& \text { الإطار النظري و الدر اسات السابقة }
\end{aligned}
$$

السلوك اللاجتماعى:

اصبح السلوك اللااجتماعى ظاهرة ذات أهية كبيرة في الوقت الحاضر، نظرا لتزايد معدلات حدوثه وانتثاره كمشكلة مزعجة لكل من البيت والمدرسة والمجتمع خلال فترة المراهقة، كما حظيت العوامل والمتغيرات الكامنة وراءه باهتمام العديد من الباحثين كمحاولة هندية لتفسيره وفهم تطوره واستمراره، حيث أصبحت المشكلات السلوكية في البيئة المدرسية من اهم المشكلات التي يواجهها القائمون على العملية التعليمية التريوية، ومن أكثر العوامل التي تشكل خطراً على النظام التعليمي برمته، كونها تقلل من فرص توافق الطالب واستثماره لطاقته وتعيق تعلمه وتحد من فاعليته، وتستهلك الكثير من جهده الموجه للاراسة وجزء كبير من طاقة المعلم الموجهة للتعليم (Hemphill, 2012, 301-317). ويتضمن السلوك اللاجتماعى مجموعة من السلوكيات التي من شانها أن تحدث ضرراً بالعلاقات بين الأثخاص، والتي قد تندرج أيضا تحت فئة السلوك الأخلاقي، فالسلوكيات اللااجتماعية هي تلك السلوكيات التي تسبب أذى للأثخاص الأخرين، وتلحق الضرر بالعلاقات بين الثخصية، وتتحدى النظام الاجتماعي والقيم الثقافية بطريقة لا تبررها القيم الاجتماعية الإيجابية، وكذلك السلوكيات في أي مناقشة شاملة للسلوك اللاجتماعى ( Torry

(\& Billick, 2011, 275-285

ويشير الاليل التشخيصي والأخصائي الخامس للاضطرابات العقلية بان السلوك

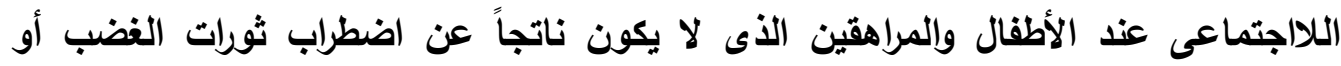
اضطراب عقلي (كاضطراب المسلك أو اضطراب ثورات الغضب المتقطعة أو اضطراب 
الشخصية المعادية للمجتمع، وتتضمن الأمثلة على هذه الفئة السلوكيات اللاجتماعية

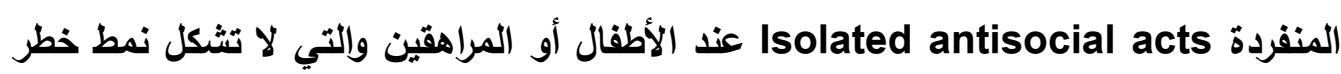
من السلوك المُعادي للمجتمع (APA, 2013).

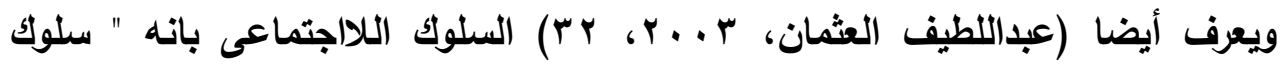

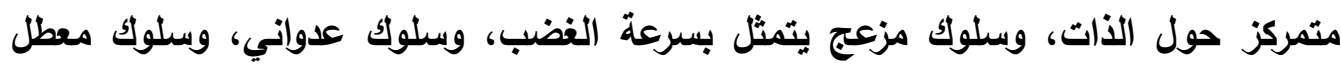
للنشاطات الجارية وسلوك يتصف بكثرة الطلبات والفوضى والعصيان وعدم الاستجابة والقسوة والتصرفات الفوضوية والثغب وإلكنب والنغ والتخريب. السلوك اللااجتماعى يشير إلى "مجموعة من السلوكيات المتمركزة حول الذات والسلوكيات المزعجة للمحيطين بالفرد، وغالباً ما تكون هذه السلوكيات غير مقبولة اجتماعيا سواء كاتت داخل المدرسة أو خارجها، وتظهر هذه السلوكيات على شكل أنماط سلوكية والهات متعددة كسرعة الغضب والسلوك العدواني بأثكاله المختلفة، والسلوكيات المعطلة للنشاطات الجارية والسلوك الفوضوي والتمرد والعصيان والسلوك الإنسحابى للمعلم أو ولى الأمر،

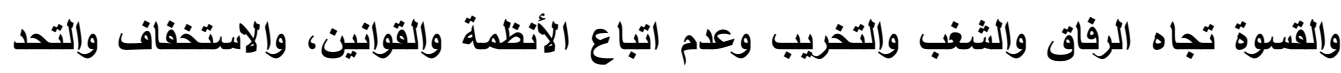

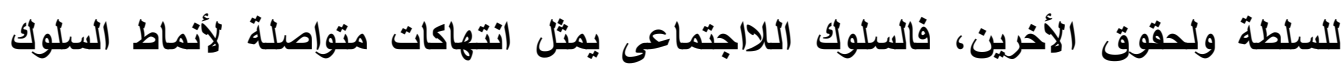

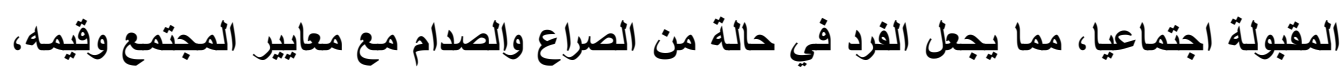
وتظهر هذه المشكلات خلال سنوات المدرسة، وتزداد بشكل خاص في مرحلة المراهقة وقد

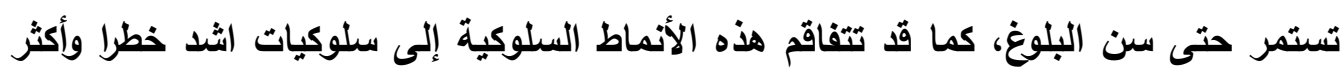
ضرراً، حيث أنها قد تتطور فيما بعد إلى سلوك إجرامي (449-Mayer, 2001, 414). ويتضمن السلوك اللااجتماعى "مجموعة من السلوكيات التي من شانها أن تحدث ضراً بالعلاقات بين الأشخاص، والتي قد تتدرج أيضاً تحت فئة السلوك اللاأخلاقي، فالسلوكيات

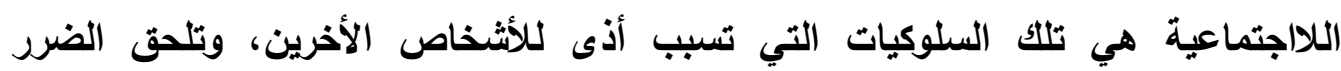
بالعلاقات بين الثخصية، وتتحدى النظام الاجتماعي والقيم الثقافية بطريقة لا تبررها القيم الاجتماعية الإيجابية، وكذلك السلوكيات التي تنطوي على انتهاك القانون والأعراف السائدة،

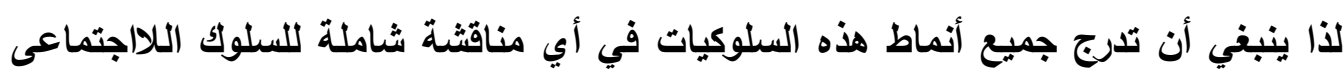
.(Baumesier \& lobbestael, 2011, 635-649) 


\section{(ثانباً) تصنيف السلوك اللااجتماعى:}

تتعدد المظاهر الثائعة للسلوك اللااجتماعى بحسب ما يراه علماء التربية وعلم النفس، وهو يظهر من خلال التصنيفات الآتية:

1) تصنيف "جوود ويروفي" (Good \& Broophy, 1994): يصنف السلوكيات اللاجتماعية إلى ثلاثة أنواع هي:

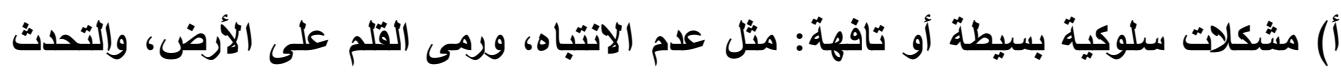

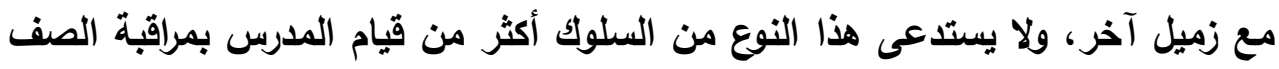
الاراسي. ب) مشكلات سلوكية مستمرة: ويقصد بها المشكلات التي تستمر على الرغم من محاولات

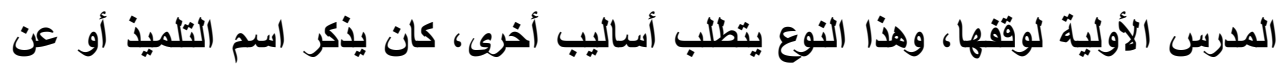

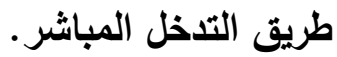
ج) مشكلات سلوكية كبيرة أو رئيسية: مثل سلوك التهجم، أو تعريض الأخرين للأذى وغيرها

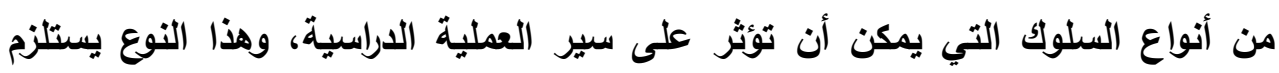

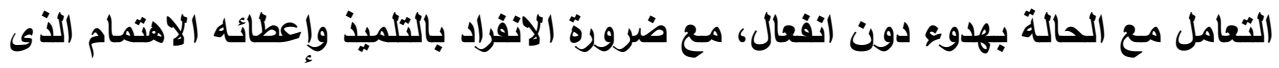

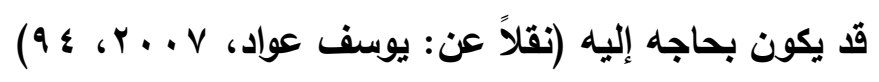

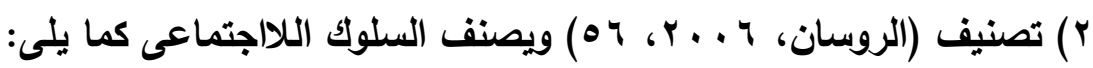

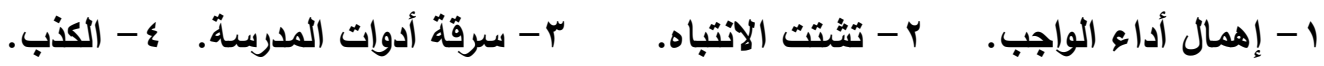

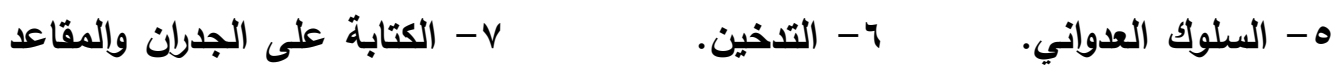

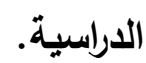

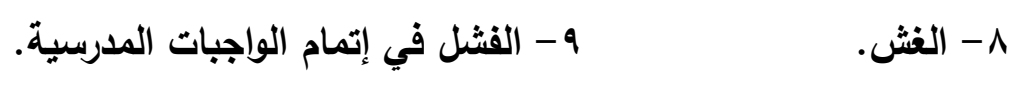

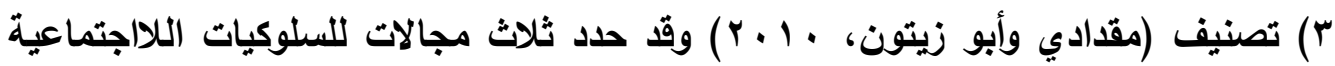

أ) سرعة الغضب: ويقصد بها السلوكيات التي تعكس التمركز حول الذات كالأنانية وحب التملك والإزعاج، إضافة إلى السلوكيات المزعجة التي تؤدى إلى رفض الرفات التهاق.

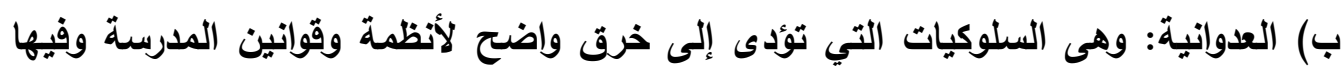
اعتاء وإيذاء للآخرين؛ مما ينتج عنها علاقات متوترة مع الرفاق للفرد. 
ج) كثرة الطلبات الفوضوية: ويقصد بها السلوكيات التي تعرقل سير النثاطات التعليمية وتضع كما كثيراً من المطالب غير المناسبة على الآخرين.

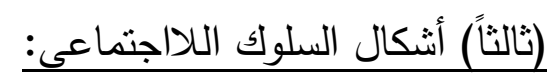

يتجلى السلوك اللااجتماعى في عدد من الأثنكال والمظاهر التي تتناولها العديد من الباحثين، ومنهم (Mcevoy, 2000) ومن هذه الأثكال: 1) التلميذ الذى يأتي إلى الصف الدراسي متأخراً، أو يخرج من الصف مبكراً ويثكل متكرر

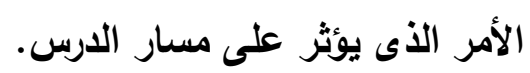

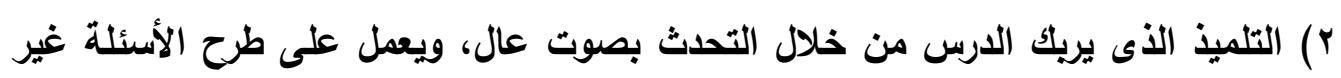
المناسبة ويعيدة عن الدرس.

؟) التلميذ الذى يكثر من التحدث مع زملائه أثناء سير الدرس.

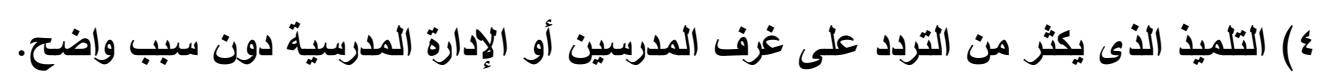

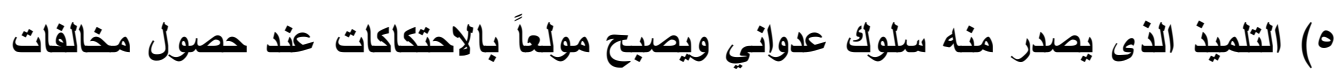

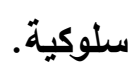

\) التلميذ الذى يعد مصدراً لتهديدات بانية أو لفظية للمطلمين أو لأى عضو في المدرسة.

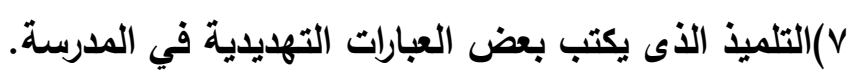

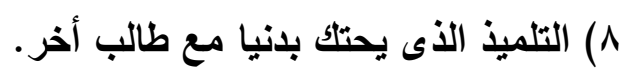
9) التلميذ الذى يوجه ألفاظاً مخلة ونابية لأحد أعضاء البيئة التعليمية أو لطالب أخر. الدر اسات السابقة

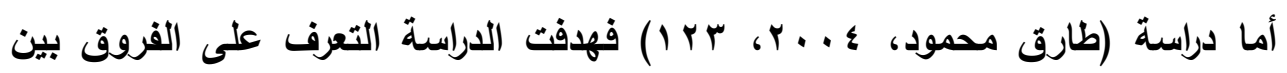

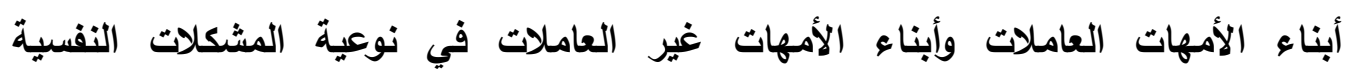

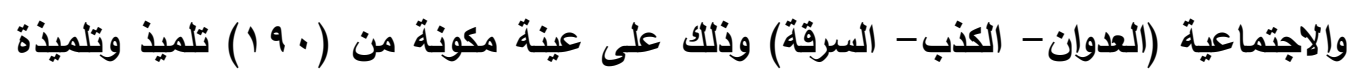

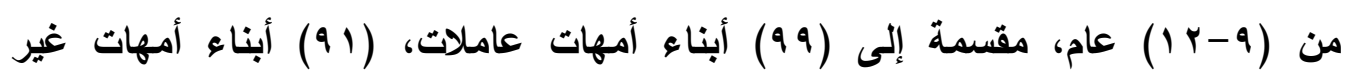

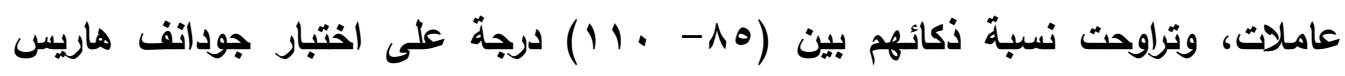

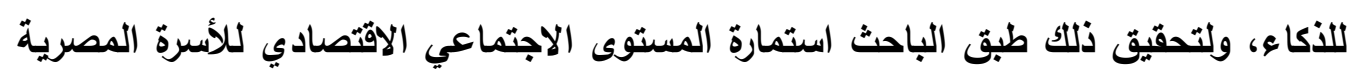

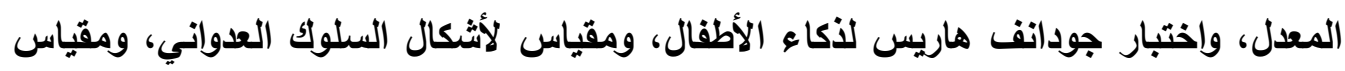

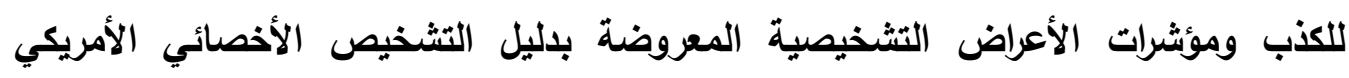


الطبعة الرابعة الصادر عن جمعية الطب النفسي الأمريكي. وأشارت النتائج إلى انه لا توجد علاقة ذات دلالة إحصائية بين عمالة الأمهات وسرقة الأبناء. وعن أساليب الرعاية الوالدية والسلوكيات الانفعالية اللااجتماعية لاى الطلبة الأكور

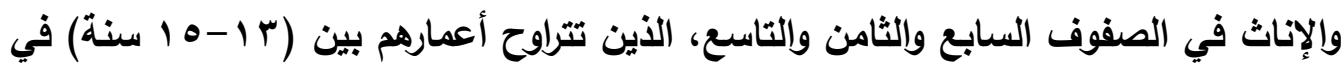

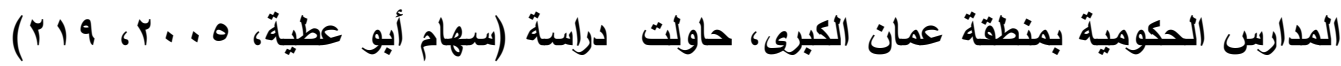
التعرف على اثر أساليب الرعاية الوالدية في السلوكيات الانفعالية اللااجتماعية، تم استخدام مقياس الرعاية الوالدية الذى طبق بطريقة جمعية، ومقياس السلوكيات الانفعالية اللااجتماعية الذى طبق بطريقة فردية، وذلك على الطلبة الذين حددت إدارة المدرسة بأنهم حولوا إلى المرشد أو مدير المدرسة بسبب مشكلات تتعلق بسلوكيات انفعالية لا اجتماعية

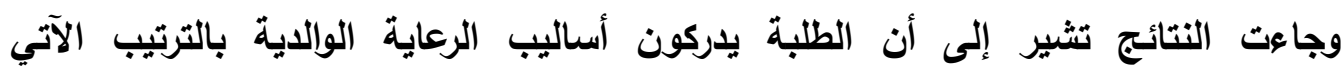

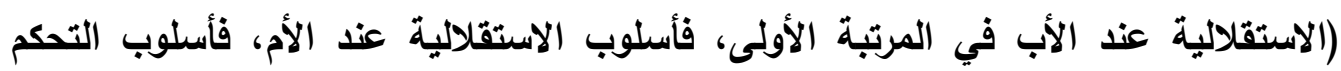

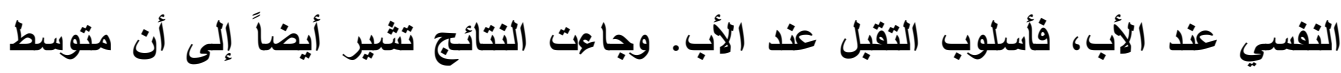
السلوكيات الانفعالية عند الأكور اعلى مما هي عليه مما هي عليه الحال عند الإناث، والسلوكيات اللااجتماعية اعلى عند الإناث مما هي عليه الحال عند الأكور.

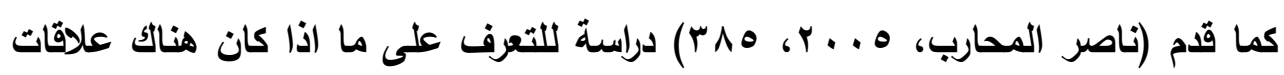

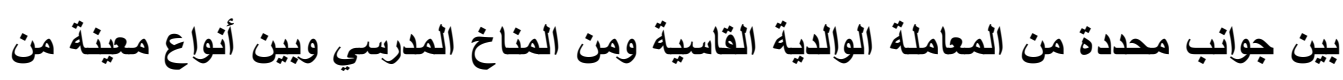

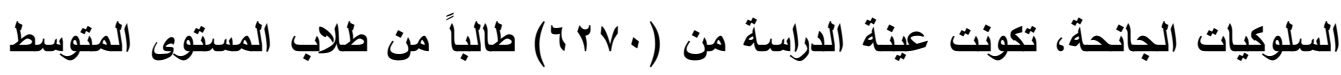
والثانوي في مدارس متوسطة وثانوية من المدن الرئيسية في مناطق المملكة العربية السعودية. أظهرت النتائج أن معاملة الإدارة المدرسية هي الأكثر قدرة على التنبؤ بالسلوكيات

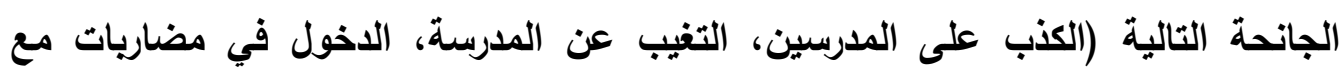

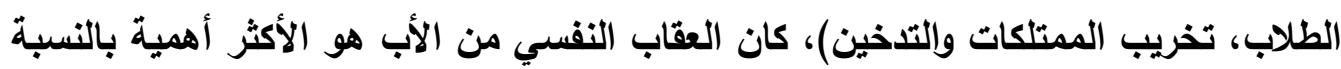

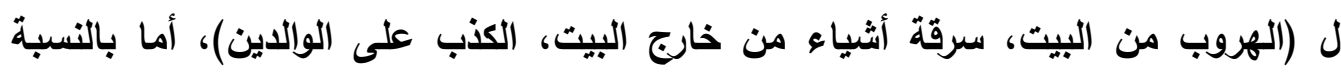

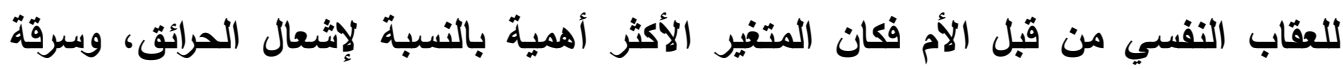
الأشياء من البيت.

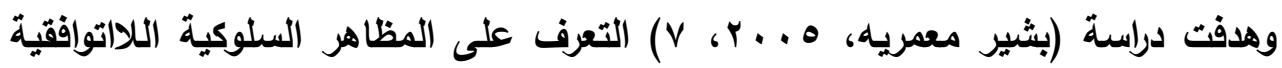

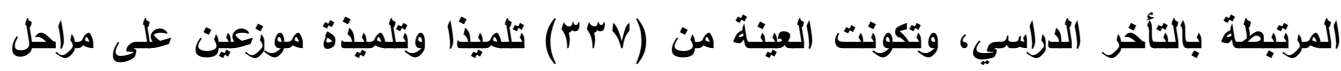


التعليم الابتائي والإكمالي والثانوي، واستخدم الباحث أداة لجمع المعلومات عن متفير الاراسة، وتم التوصل إلى أن اهم المظاهر السلوكية اللااتوافقية التي ترتبط بالتأخر الدراسي وهى عدم القيام بالواجبات الدراسية، والغش في الامتحانات، الكسل، عدم الاعتناء بالأدوات الات

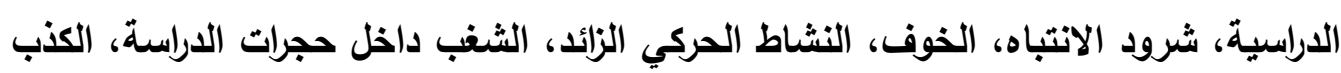
والاحتيال، تعطيل المعلم عن الدرس. لترود الاتهاه.

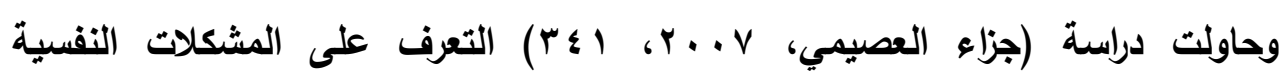
الموجودة في مراحل التعليم العام، الابتدائي، المتوسط، الثانوي، وهذه المشكلات هي (الخوف

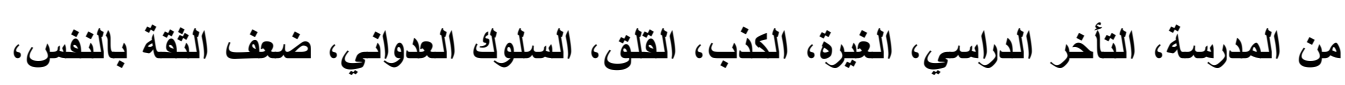
الشعور بالنقص). باستخدام مقياس المشكلات النفسية الذى اعده الباحث لاستخدامه مع عينة الاراسة، حيث كثفت النتائج عن وجود فروق بين متوسطات درجات بات مشكلات الطلاب النفسية في مراحل التعليم العام، وكانت الفروق في اتجاه طلاب التعليم الابتدائي.

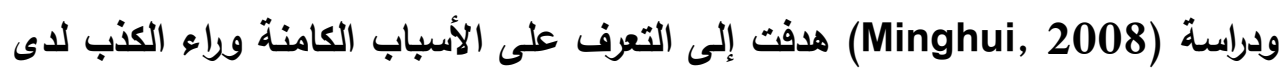

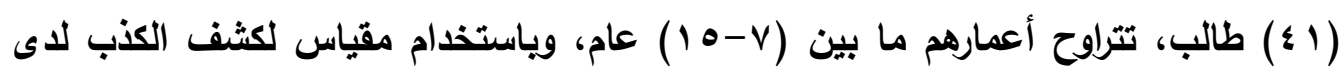

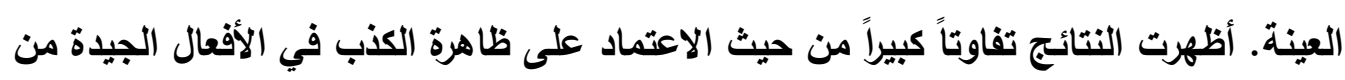
اجل الحصول على التقدير، نظراً لاختلاف ثقافاتهم واختلاف الأطفال أيضاً بسبب استجابتهم

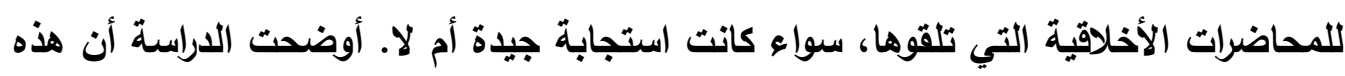
الظاهرة ناتجة عن وجود فجوة في حدود الثقة بين الطلاب والمجتمع، حيث اتخذ الأطفال هذا

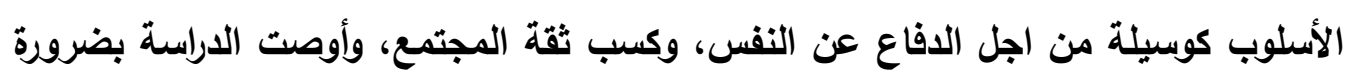

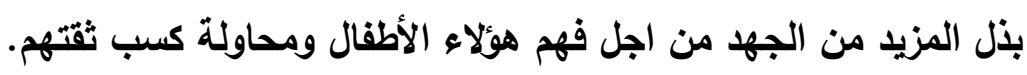
كما اهتمت دراسة (1014-Murray, 2009, 1001) بالتعرف على القيم السياسية والقيم الأخلاقية في المدارس وما دور المعلم في تنميتها لدى الطلاب. وتوصلت الدراسة إلى دالى

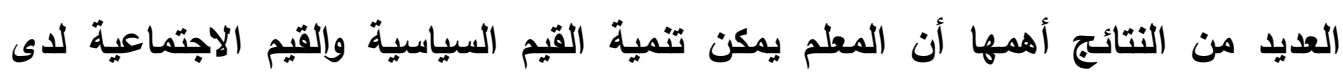

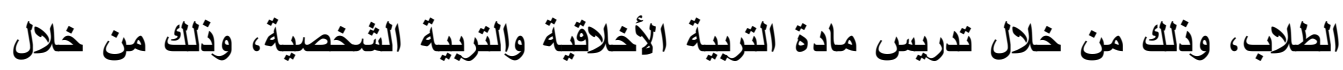
عملية التدريس يمكن تنمية قيم الأخلاق والعدالة وتعليم الديمقراطية لدى الطلاب.

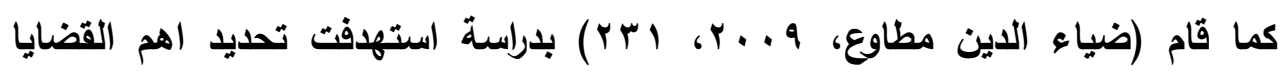

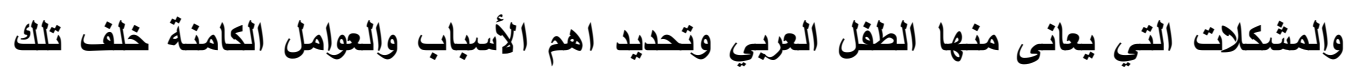


المشكلات، وذلك على عينة مكونة من ( (10) من الرجال والسيدات المهتمين بالطفولة ومشكلاتها من المعلمين وأولياء الأمور والعاملين بدور الرعاية الاجتماعية والصحية وأعضاء ولهاء هيئة التدريس والأطباء في (أبها، المنصورة). وقد استخدم الباحث استبانة للخبراء والمعنين والمسئولين والمهتمين بقضايا الطفولة في بعض البلدان العربية حول قضايا ومشكلات الطقولة في الوطن العربي والأسباب الكامنة خلفها. أظهرت نتائج الدراسة أن مجال المشكلات السلوكية تمثل ه \% من من المشكلات التي يعانى منها الطقل العربي تشمل مشكلات

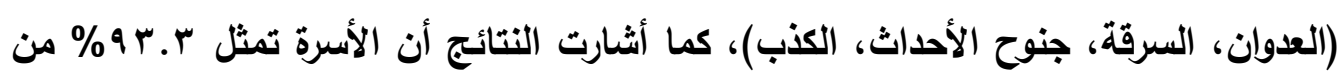
الأسباب التقصيرية الكامنة خلف مشكلات الطقل العربي. دراسة (Xu, f, 2010, 581-596) هدفت تحديد العلاقة بين الكنب وقول الحقيقة

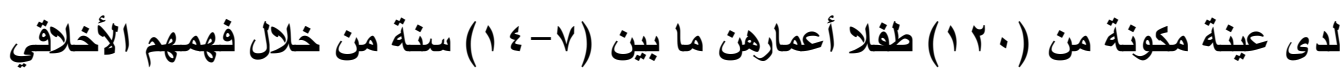
للكذب، وحقيقة سلوك الكذب لايهم في مواقف الكياسة. أظهرت نتائج الدراسة انه مع الته التقام

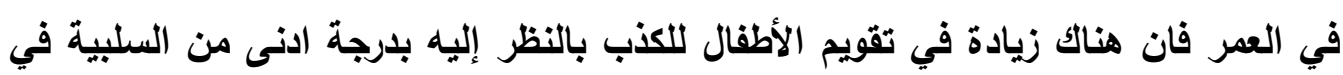
المواقف التي تحتاج إلى كياسة، وهم انفسهم يميلون إلى قول الكذب في مواقف مشابهة

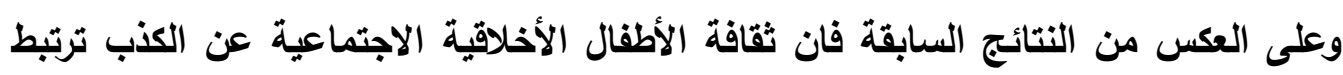
بشكل وثيق بسلوكهم الفعلي ويالتحديد عندما يقوم الأطفال بتبريز أحكامهم الأخلاقية المحدة، فهي إنما ترتبط بدوافعهم الحقيقية للكذب أو قول الحقيقة في المواقف التي تحتاج إلى الكياسة.

أجريت دراسة (Javeed, 2012, 67) في الهند بهذف التعرف على مستوى العزلة الاجتماعية ومفهوم الذات لاى طلبة المرحلة الثانوية في ضوء متفير الجنس، تكونت عينة

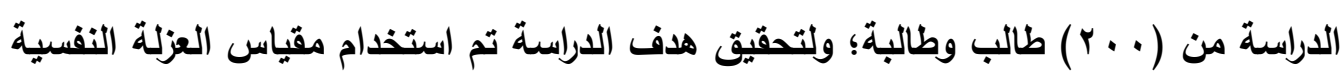

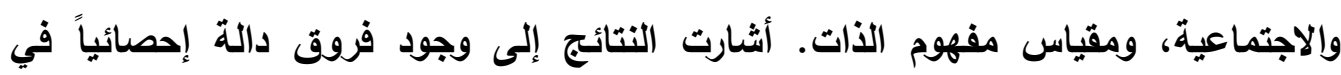

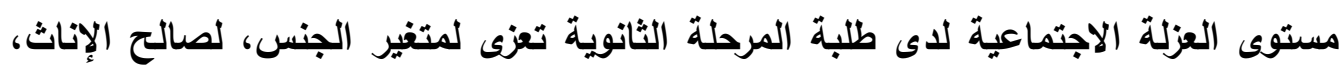

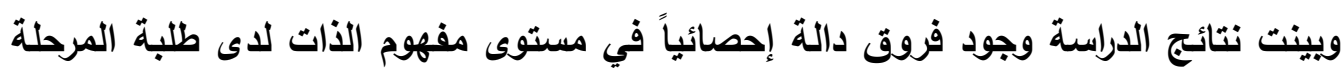
الثانوية تعزى لمتغير الجنس ولصالح الأكور. كما قام (Teasdale, 2013) بدراسة في الولايات المتحدة الأمريكية هدفت تعرف

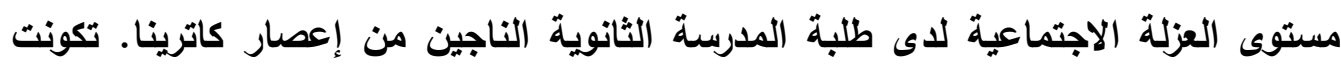


عينة الدراسة من (r^) طالبا وطالبة من طلبة المدارس الثانوية؛ ولتحقيق هدف الدراسة تم

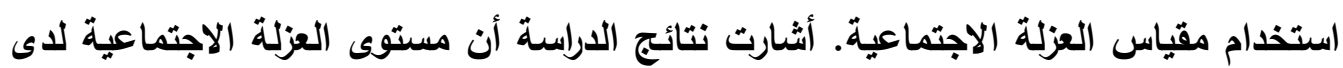

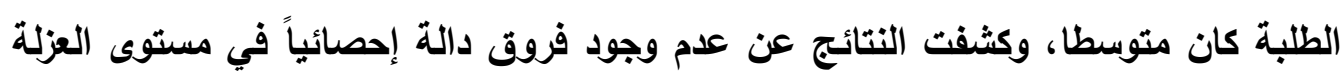
الاجتماعية تعزى إلى الجنس. بهدف الكثف عن العلاقة بين إساءة المعاملة الوالدية كما يدركها الأبناء والكذب لاعثى الدئ

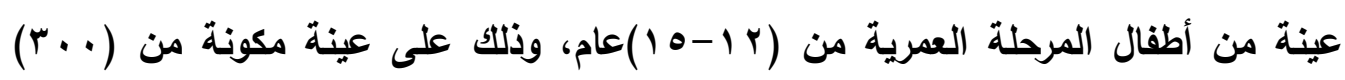
تلميذ وتلميذة.

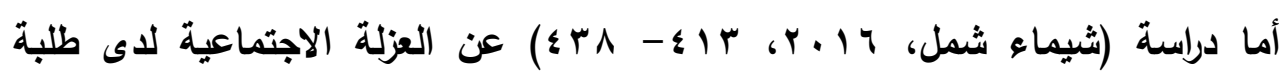
المرحلة المتوسطة". هدفت الدراسة إلى الكثف عن مستوى العزلة الاجتماعية لاى عينة

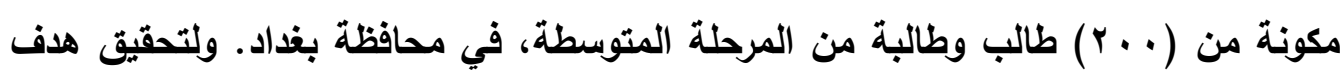

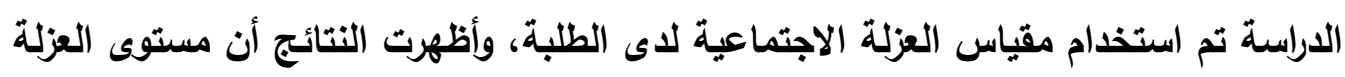
الاجتماعية لا يختلف باختلاف جنس الطالب.

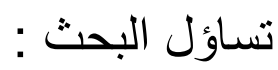
" ما أنماط السلوك اللاإجتماعى الشائعة لدى التلاميذ المرحلة الإعداديةّ؟ " إجر اعات البماط البطو أولاً:منهج البحث: أبث:

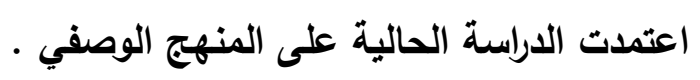
ثانياً:عينة البحث: أبمدا: تم اختيار عينة الدراسة الاستطلاعية بطريقة عشوائية من طلاب المرحلة الإعدادية بمراحلها

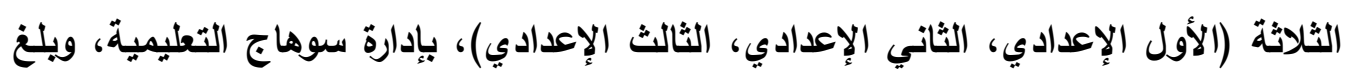

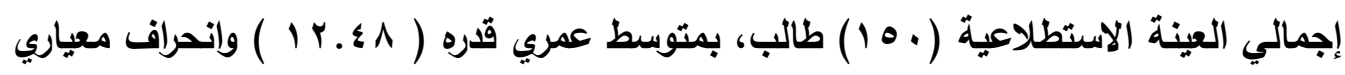

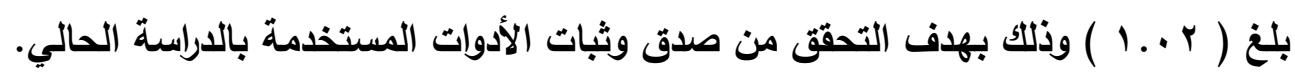

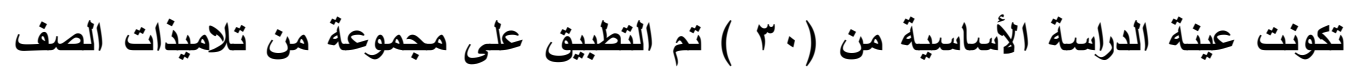

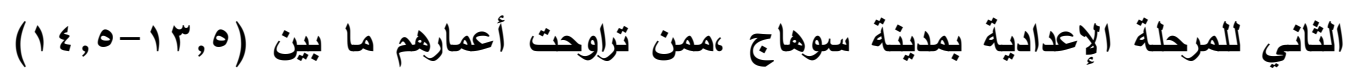
عاماً. ثالثاً:أدواث البحث: 


\section{1 - مقياس السلوك اللاإجتماعي • إعداد : الباحثة. (ه) الخصائص السيكومترية للمقياس: صدق المقياس: (1) صدق المحكمين( الصدق الظاهري):} تم عرض مقياس السلوكيات اللااجتماعية في صورته الأولية المكون من (• (^) فقرة ممثلة لأربع أبعاد السلوكيات اللااجتماعية، على (Y (Y) محكمين من أساتذة كلية التربية والآداب بجامعة جنوب الوادي وجامعة سوهاج، حيث طُب منهم قراعة فقرات الاختبار والحكم عليها من حيث مدى وضوحها وملاءمتها للهدف الذي وضعت من أجله المقياس، واستبعاد العبارات غير الملائمة أو إدخال التعديلات المناسبة لتصحيحية للصياغة أو إضافة فقرات جديدة بما يخدم الهذف من المقياس ويزيد من قيمته.

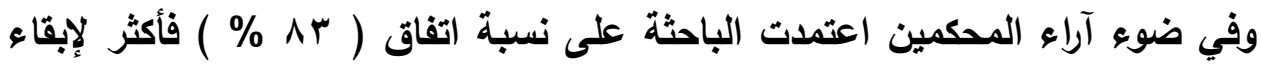
الفقرة في الاختبار واعتمادا على ذلك تم حذف (ب) فقرات لم تحظى بنسبة الاتفاق المحدةة، وتعديل (r) فقرات من حيث الصياغة كما هو مبين في الجدول التالي :

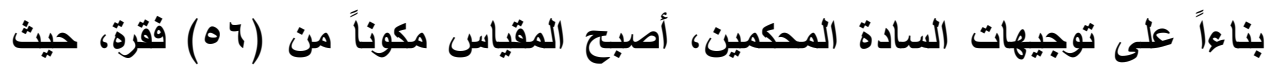
شكلت الصورة الأولية للمقياس التي تم تطبيقها على العينة الاستطلاعية التي يتم من خلالها منها التحقق من الصدق وللمقياس.

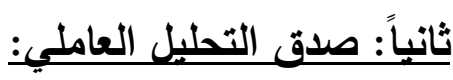
قامت الباحثة بتقدير صدق التحليل العاملي للمقياس، وذلك للتعرف علي واقع التركيب العاملي له، ولتحقيق ذلك أجرت الباحثة التحليل العاملي لاستجابات العينة استطلاعية التي بلفت(10.1 من تلاميذ المرحلة الإعدادية، علي فقرات المقياس البالغ عددها(؟ه فقرة) باستخدام طريقة المحاور الرئيسية (Principal component's) تبعه إجراء تدوير متعامد

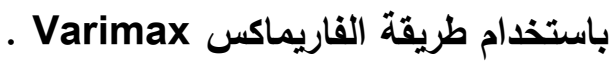
مراحل إجراء التحليل العاملي لمقياس أنماط السلوك اللااجتماعي: * التأكد من مدي مناسبة مصفوفة الارتباطات لفقرات المقياس: قامت الباحثة بإجراء التحليل العاملي، وأسفرت النتائج علي: 
1 - أغلب معاملات الارتباط تتعدي( • r. · ) ودالة إحصائياً.

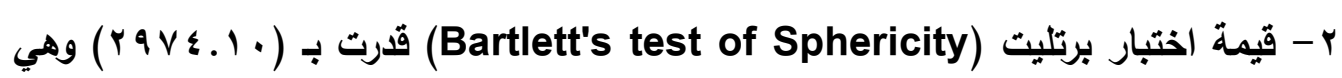
قيمة دالة عند (1 (...) وهذا يدل علي أن المصفوفة يتوفر بها الحد الأدنى من الارتباطات التي تجعلها قابلة للتحليل العاملي.

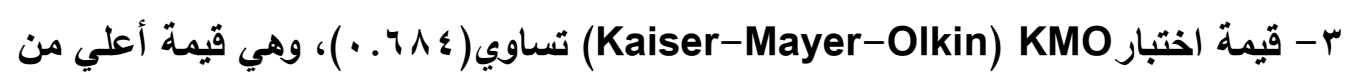

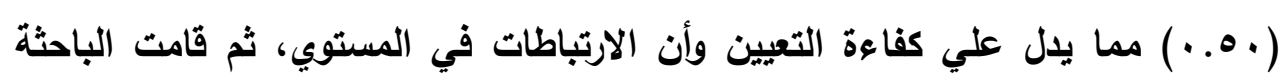
بتطبيق مقياس ( MSA ) (Measures of Sampling Adequacy) (Mوفي محكات

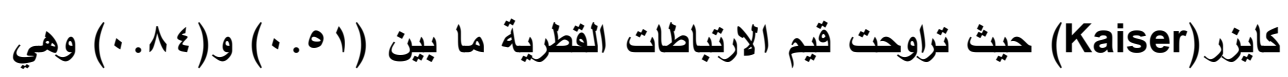

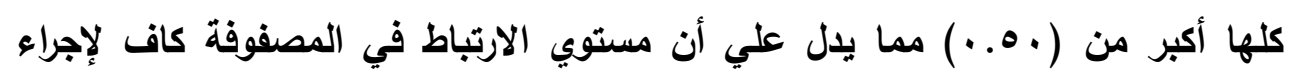
التحليل العاملي.

* إجراء التحليل العاملي عن طريق المحاور الأساسية، واستخدام واحد صحيح علي الأقل

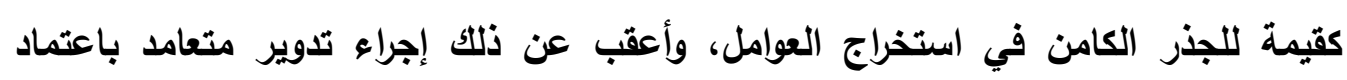
طريقة الفاريماكس، كما هو موضح في الجدول التالي: 
جدول ( الاع ـ ) مصفوفة تشبعات فقرات مقياس أنماط السلوك اللااجتماعي لاي طلبة المرحلة الإعدادية باستخدام التحليل العاملي عن طريق المحاور الأساسية بعد التدوير المتعامد بطريقة فاريماكس

\begin{tabular}{|c|c|c|c|c|}
\hline العامل الرابع & العامل الثالث & العامل الثاني & العامل الأول & الفقرات \\
\hline $.1 Y \Lambda=$ & $\because \varepsilon$. & .117 & . YMI & 1 \\
\hline $.90 \mathrm{~V}$ & .919 & $\because \wedge r$ & $\because r \leqslant V$ & r \\
\hline$\because r \vee q$ & .174 & $\cdot|v|$ & . OY & $r$ \\
\hline .491 & $\cdot$ ror &.$r \vee v$ & $\because r r$ & $\varepsilon$ \\
\hline .170 & $\cdot . \varepsilon r r$ &.$Y Y r$ & 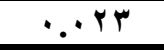 & 0 \\
\hline .47. &. $.1 Y V$ & $\because 1 \leq r$ &. $.1 Y V$ & 7 \\
\hline$\because .1 \wedge r$ & $.19 \varepsilon$ & $.10 \mathrm{~V}$ & $.0 Y$. & $\mathrm{V}$ \\
\hline$\because M^{\prime}$ & .18. &.$r \vee q$ & $\because Y \vee \Delta$ & $\Lambda$ \\
\hline.$Y 7$. & .070 & $\because Y 1 \leq$ & $.174=$ & 9 \\
\hline .0 .1 & $\because 99$ &.$Y Y T$ & $\cdot r r$. & 1. \\
\hline 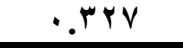 & .174 & . & $.0 \cdot 1$ & 11 \\
\hline$\cdot .1 \cdot \varepsilon$ &.$r \cdot 7$ & $\cdot r \cdot \theta$ & $\because Y Y \varepsilon$ & $1 r$ \\
\hline$\cdot 1 \cdot r=$ & $.0 . V$ &. $.1 \cdot 1$ & .117 & $1 \%$ \\
\hline$\cdot r v r$ & .119 & $\because 11$. & $\because O H=$ & $1 \leq$ \\
\hline $.11 r$ & $\cdot r \cdot r$ &.$Y 1 T$ & $.0 \% 1$ & 10 \\
\hline$\because Y \leqslant 0$ & $\because 9 \mathrm{~V}$ &. .210 & $\because r O r$ & 17 \\
\hline $.10 \leq$ & $\cdot . \leqslant \leqslant Y$ & .011 &. $.10 Y$ & $1 V$ \\
\hline$\because r v \varepsilon$ & . YMI & $\because Y \vee A$ &. .11. & 11 \\
\hline .179 & .100 & $\because Y r$. &. rYo & 19 \\
\hline .111 & $\because r V r$ & $\because \leqslant 0 \wedge$ & $\because Y 1$. & $r$. \\
\hline .879 &. $.8 Y 7$ & $\because Y r$. & $.1 Y \varepsilon-$ & YI \\
\hline .0 .0 &.$r r q$ & .119 & .174 & Yr \\
\hline $.1 r r$ & 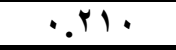 & $.1 \leq 1$ & $.01 \leq$ & $r r$ \\
\hline$\cdot r \cdot 1$ & $.1 \leq$ &..$\leqslant 99$ & $. .1 \leq 0$ & $r \leq$ \\
\hline$\because .4 \wedge 9$ & $.0 Y \wedge$ & $.1 Y r$ &.$r Y q$ & ro \\
\hline $.0 \leq 0$ & $.149-$ & $.1 Y r$ & $. r \mid r$ & $r 7$ \\
\hline$. r+1$ & $.11 \%$ & .194 & .010 & $r V$ \\
\hline. $.11 r$ &. YOr & $.0 \wedge 1$ & $.170-$ & $r \wedge$ \\
\hline. $.1 \mathrm{VH}$ &..$\leqslant 1 \%$ & $\because Y O Y$ & .194 & rq \\
\hline .07. & $\because Y Y I$ &.$Y M I$ & $.1 \leqslant r-$ & $r$. \\
\hline$. r \mid r$ & $.11 r$ &.$Y Y V$ & .9 .0 & $r$ \\
\hline$\because 94$ &. .17. &..$\leqslant V 1$ &.$Y Y Y$ & $r r$ \\
\hline . YYE &..$\leqslant \leqslant 9$ &.$Y M I$ &. .MY & $r r$ \\
\hline$\because \leqslant V \leqslant$ & .179 & 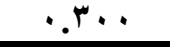 & $\cdot 1 \cdot r$ & $r \varepsilon$ \\
\hline .079 & 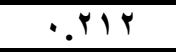 & $\cdot r \cdot v$ & $\because 49 \leq$ & ro \\
\hline
\end{tabular}




\begin{tabular}{|c|c|c|c|c|}
\hline العامل الرابع & العامل الثالث & العامل الثاني & العامل الأول & الفقرات \\
\hline .170 &. .971 & $\cdot r q r$ &. YYr & rq \\
\hline.$r q r$ & $.0 Y$. & $. r \leqslant q$ & $\because 91$ & $r v$ \\
\hline$. r \leqslant q$ & .117 &.$r \ldots$ &. .191 & $\mu \wedge$ \\
\hline.$Y 9 Y$ &.$Y M I$ & .170 &.$r .0$ & $r q$ \\
\hline$\because Y \cdot Y$ & $\cdot Y \cdot V$ &.$\leqslant Y 0$ & $.10 \leq$ & $\varepsilon$ \\
\hline$. . M 1 \leq$ &..$r \wedge q$ & $. .174-$ & $\because I V r$ & $\sum 1$ \\
\hline..$\leqslant r q$ &.$Y 91$ & $\because \wedge \mu_{-}$ & $\cdot r \cdot r$ & $\varepsilon r$ \\
\hline.$r V Y$ & $.1 \wedge \theta_{-}$ & $. .1 \leq 7$ & 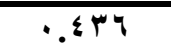 & $\varepsilon r$ \\
\hline$\because Y q \varepsilon$ & $.1 Y r$ & $.0 \wedge r$ & $\cdot r \leqslant r-$ & $\varepsilon \varepsilon$ \\
\hline$\because Y \leqslant \varepsilon$ & $.0 \%$. & $\because T^{Y}=$ & $\cdot . r \cdot 1$ & $\varepsilon 0$ \\
\hline.$r \wedge q$ & •.YTE - & . MYI &. $.1 \wedge \wedge$ & $\varepsilon 7$ \\
\hline.. $\mathrm{r4 \Lambda}$ &.$Y 11$ &. .171 & $.0 \wedge 1$ & $\leqslant V$ \\
\hline .11. &.$r^{\mu}$ &..$\leqslant Y T$ &. . rYr & $\varepsilon \Lambda$ \\
\hline .10 & $\because E V Y$ & . & $\because 00$ & $\varepsilon 9$ \\
\hline. .519 & .979 &.$r r \varepsilon$ & $\because .00$ & 0. \\
\hline .111 &.$Y 9 q$ & $.1 \wedge r$ & $\because \leqslant Y 0$ & 01 \\
\hline.$r v V$ & .119 & .001 & $\cdot Y \leqslant \varepsilon$ & Or \\
\hline .111 & $\because r q$. &.$r r r$ & $.1 \cdot 7$ & or \\
\hline$\because \leqslant r 0$ & $.1 \leqslant V=$ & 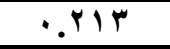 & $\because r \leq \varepsilon$ & $0 \leq$ \\
\hline$\because r \cdot 0$ &.$\mu 1 \varepsilon$ &..$r \cdot 7$ & .1801 & 00 \\
\hline. rqr &.$r M r$ &. $.7 V \varepsilon$ & $. \mu / r$ & 07 \\
\hline r.ArA & $r . \wedge \leq r$ & $r . \leqslant \leq 1$ & r.trq & الجذر الكامن \\
\hline$r \cdot . r V$ & $r \cdot . r 1$ & $Y \leqslant .01$ & ro.9. & نسبة التباين المفسر \\
\hline
\end{tabular}

يتضح من الجدول (1 - ؛ ) أن التحليل العاملي لمقياس أنماط السلوك التلاجتماعي أسفر علي أربعة عوامل وهي (أزمة القيم - العزلة الاجتماعية - الكذب - السرقة ). (ثالثاً) صدق المقارنة الطرفية(الصدق التمبيزي): تم أخذ الدرجة الكلية لكل بعد من أبعاد مقياس أنماط السلوك اللااجتماعي محكاً للحكم على فلى

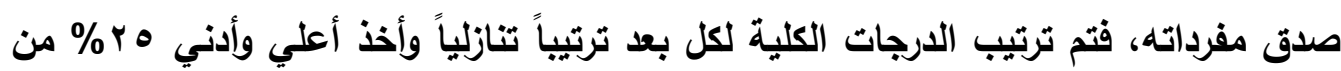

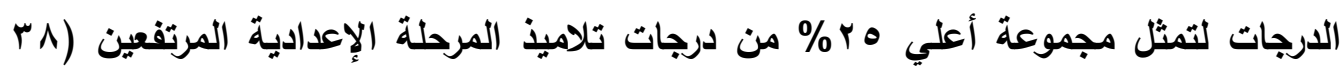

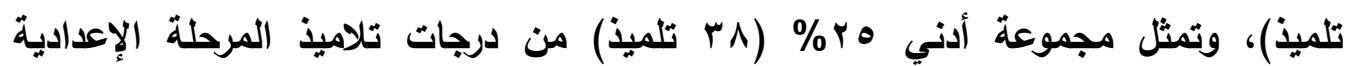
المنخفضين، وياستخدام اختبار "ت" في المقارنة بين المتوسطات لمعرفة معاملات التمييز بين المرتفعين والمنخفضين كما هو موضح بالجدول التالي: 


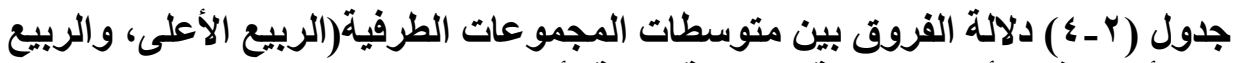

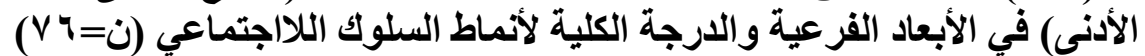

\begin{tabular}{|c|c|c|c|c|c|c|c|}
\hline \multirow{2}{*}{ مستوي الدلالة } & \multirow{2}{*}{ الحرجة } & \multirow{2}{*}{ قيمة (ت) } & \multicolumn{2}{|c|}{ مجموعة الربيع الأدنى } & \multicolumn{2}{|c|}{ مجموعة الربيع الأعلى } & \multirow{2}{*}{ الأبعاد } \\
\hline & & & $\varepsilon$ & p & $\varepsilon$ & p & \\
\hline دالة عند 1 •. & \multirow{5}{*}{$V \varepsilon$} & $* *$ *.. \1 & $\because \leqslant Y$ & $1 . .0$ & $r . r q$ & 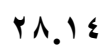 & العزلة الاجتماعية \\
\hline دالة عند 1 ... & & $* * 10.7 \varepsilon$ & 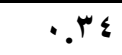 & $1 . .10$ & Q & r.. & السرقة \\
\hline دالة عند 1 •.. & & $* * 1 \leqslant . \leqslant 0$ &. .57 & $1 \cdot . \leqslant \varepsilon$ & $\varepsilon . \mu r$ & ro.V & الكذب \\
\hline دالة عند 1 .. & & $* * 10 . \mathrm{VA}$ & 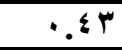 & $1 \cdot .0$ & \&.YO & $r 7 . r$ & أزمة القيم الأخلاقية \\
\hline دالة عند I .. & & $* * 1 \% .$. & $\because 9$ & $\varepsilon Y . \varepsilon$ & 19.8 & 1.4 .9 & الارجة الكلية \\
\hline
\end{tabular}

* دالة عند مستوى 0. •.

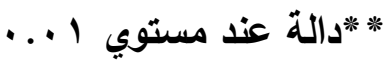
يشير الجدول (9 - \&) إلى وجود فروق ذات دلالة إحصائية بين درجات الربيع الأعلى والربيع الأدنى لدى العينة الاستطلاعية على اختبارات(العزلة الاجتماعية، السرقة، الكذب، أزمة القيم الأخلاقية) والدرجة الكلية لقياس أنماط السلوكيات اللااجتماعية، بما يشير إلى قدرتها على البى قياس السمة المُعد من أجلها. ثثانيا: ثبات المقياس:

(1) معامل ثبات ألفا كرونباخ:

تم حساب ثبات مقياس الدافعية نحو التعلم وأبعاده الفرعية الخمسة المكون من (بr) فقرة، باستخدام معامل ثبات ألفا لكرونباخ ضمن حزمة البرامج الإحصائية المعروفة باسم SPSS ، وذلك على العينة الاستطلاعية ( ه 1 ) وكانت معاملات الثبات كالتالي :

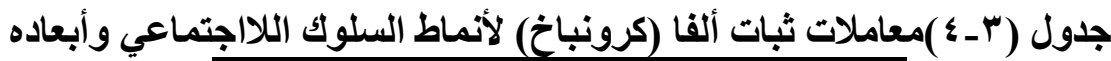

\begin{tabular}{|c|c|}
\hline معامل ثبات الفا كرونباخ & 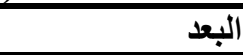 \\
\hline$* * . .790$ & العزلة الاجتماعية \\
\hline$* * . . v 1 \%$ & السرقة \\
\hline$* * . . V \backslash \leqslant$ & الكنب \\
\hline$* * . . \vee 10$ & أزمة القيم الأخلاقية \\
\hline$* * . . V T \leq$ & المقياس الكلي \\
\hline
\end{tabular}

* دالة عند مستوى ه ... *دالة عند مستوي I +... 
يتضح من جدول (• (1- ) أن قيم معامل الثبات مرتفعة، حيث أن جميع معاملات الثبات دالة عند مستوي 1 ... .، مما يؤكد أن المقياس الحالي وأبعاده يتميز بدرجة عالية من الثبات.

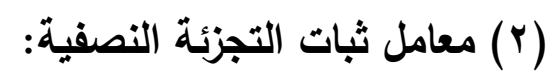

تم حساب ثبات القسمة النصفية ( فردى - زوجي ) لفقرات مقياس أنماط السلوكيات اللااجتماعية وأبعاده الفرعية الأربعة، وتصحيح الطول باستخدام معادلة سبيرمان - براون

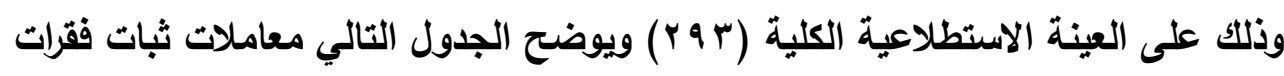
جدول ( ع ـ ) معامل ثبات القسمة النصفية لمقياس أنماط السلوكيات اللااجتماعية وأبعاده الفرعية ملئة

\begin{tabular}{|c|c|c|c|c|}
\hline \multicolumn{4}{|c|}{ 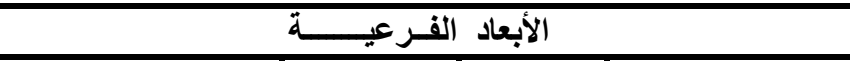 } & \multirow[b]{2}{*}{ معامل الثبات } \\
\hline أزمة القيم الأخلاقية & الكذب & السرقة & العزلة الاجتماعية & \\
\hline$\cdot .^{\wedge}$. &.$\wedge r$ & $\because V V$ & $\because v 1$ & قبل تصحيح \\
\hline$\because \wedge \wedge$ & $\because 9$ & $\because \wedge V$ &.$\wedge r$ & بعد تصحيح \\
\hline
\end{tabular}

تعتبر معاملات الثبات الموضحة بالجدول (1 1 - ؛)، معاملات ثبات مرتفعة ومطمئنة

$$
\text { نتائج البحيق. للتئ وتفسير ها }
$$
تحقيقاً لأهداف البحث تم استخراج النتائج وتفسيرها، وفيما يلي عرض لتلك التحليلات: وصف البيانات: تم استخراج المتوسط الحسابي والانحراف المعياري والوزن النسبي لأبعاد مقياس أنماط السلوك اللااجتماعى لدى تلاميذ المرحلة الإعدادية ومتغيراته الفرعية الأربعة (العزلة الاجتماعي، السرقة، الكذب، أزمة القيم)، وذلك للتعرف على أكثر تلك الأبعاد تأثيراً في

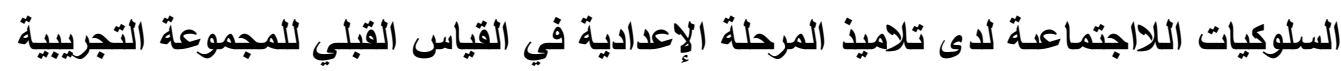
والضابطة، كما تبين ذللك النتائج التالية: 
جدول (1 ــ) المتوسط الحسابي والانحراف المعياري والوزن النسبي والأهمية النسبية لأبعاد

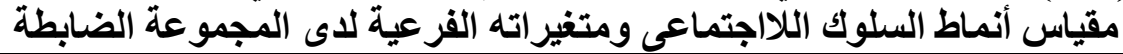

\begin{tabular}{|c|c|c|c|c|c|c|c|}
\hline النسبية & الوزن النسبي & الالنحراف & المتوسط & الإجة & الفقرات & \multicolumn{2}{|c|}{ العينة و المجالات } \\
\hline$\varepsilon$ & $\% \vee 1 . \varepsilon r$ & $r . \leqslant r$ & $r \cdot . \cdots$ & $\leqslant r$ & $1 \leqslant$ & الاجتماعية & 可 \\
\hline$r$ & $\% \vee 1.7$. & r.. $q$ & $r \cdot . \cdot v$ & $\varepsilon r$ & $1 \varepsilon$ & السرقة & \\
\hline$r$ & $\% \vee Y . \Delta 0$ & r.qr & $r \cdot . \leqslant V$ & $\leqslant r$ & $1 \varepsilon$ & الكذب & \\
\hline 1 & $\% \vee \bullet . \vee v$ & r.T. & r.or & $\leqslant r$ & $1 \varepsilon$ & أزمة القيم & नु" \\
\hline
\end{tabular}

تدل النتائج الموضحة بالجدول (1-0) احتلال بُعد أزمة القيم للمرتبة الأولى من حيث التأثير في السلوكيات اللااجتماعية لاى المجموعة الضابطة، يليه بُعد الكذب في الرتبة الثانية، ثم السرقة، وفي الأخير بُعد العزلة الاجتماعية.

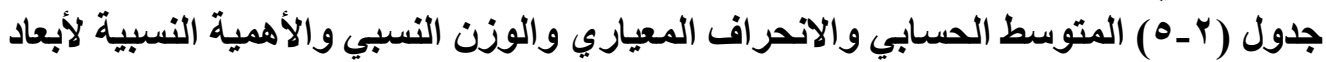

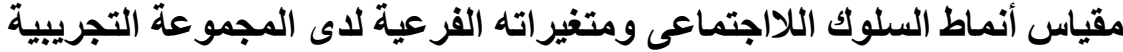

\begin{tabular}{|c|c|c|c|c|c|c|c|}
\hline النسبية & الوزن النسبي & الانحراف & المتوسط & الإرجة & الفقرات & \multicolumn{2}{|c|}{ العينة و المجالات } \\
\hline$r$ & $\% \vee 0 . Y \leq$ & $r . r v$ & r. & $\leqslant r$ & $1 \varepsilon$ & الاجتماعي & 牙器 \\
\hline$\varepsilon$ & $\% \vee r . q \wedge$ & $r .99$ & $r . \cdot v$ & $\varepsilon r$ & $1 \varepsilon$ & السرقة & ஏ \\
\hline$r$ & $\% \vee 0 . Y \leq$ & r.یI & M. & $\leqslant r$ & $1 \varepsilon$ & الكنب & 79 \\
\hline 1 & $\% \vee \neg . \cdot r$ & $\varepsilon$ & $r 1.9 r$ & $\leqslant r$ & $1 \leqslant$ & أزمة القيم & नु \\
\hline
\end{tabular}

تدل النتائج الموضحة بالجدول (r-o) احتلال بُعد أزمة القيم للمرتبة الأولى من حيث التأثير في السلوكيات اللااجتماعية لدى المجموعة التجريبية، يليه بُعد العزلة الاجتماعية في الرتبة الثانية بالتساوي مع بُعد الكذب ولكن بانخفاض في الانحراف المعياري، وفي الأخير بُعد السرقة. 
تتفق النتائج السابقة للمسح الأولي لمجتمع الدراسة قبل تطبيق البرنامج المُعد بالدراسة مع ما ذهبت إليه دراسة (نسيمة داود ،999 199) من أن تلاميذ المرحلة الإعدادية لايهم مشكلة لاتوافقية تظهر في عدة أشكال منها (العصيان، والمخالفة، وعدم الاستجابة للمعلم) وكلها

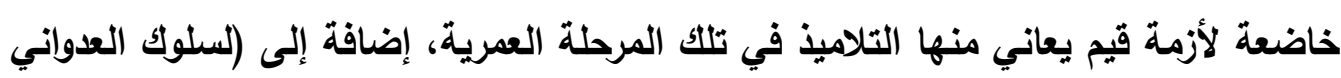

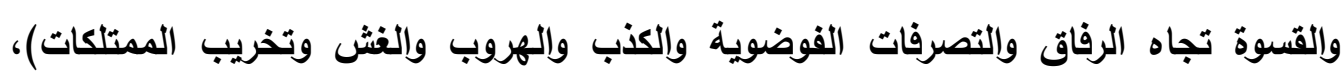
وكلها أزمات تؤدي بهم إلى سلك مسلك لاجتماعي في تصرفاتهم وتعاملاتهم اليومية مع المحيطين بهم سواء داخل الأسرة أو المدرسة أو المجتمع ككل.

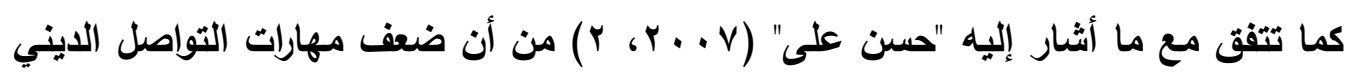

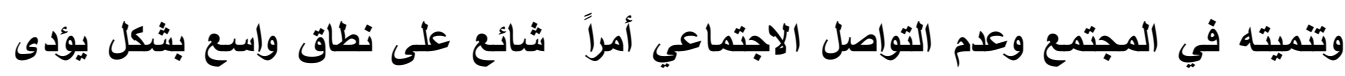

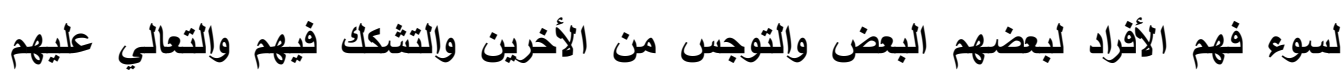

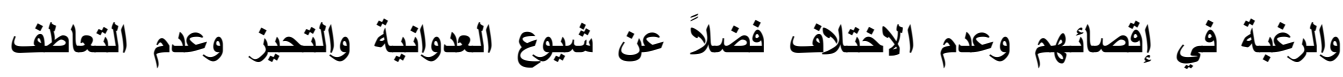
وضعف الرقابة الذاتية وتثوه الضمير .

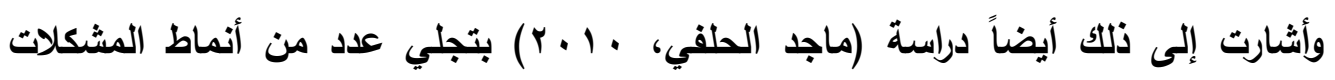
الاجتماعية نتيجة الظروف الحياتية الصعبة والتي أثرت بشكل كبير على القيم والمعايير

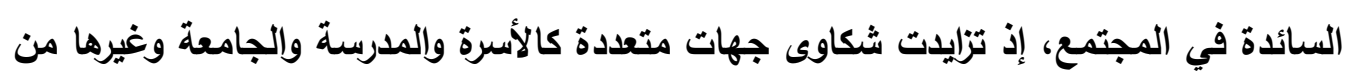
المؤسسات الأخرى في الدولة من تخلي شرائح الشباب والمراهقين عن روح التعاون والشعور بالمسؤولية وعدم الاحترام وازدياد الروح العدوانية والنزوع إلى تخريب الممتلكات والغش فئشي واستخدام الألفاظ النابية والانصراف إلى اللهو والصغب، وإنباد وظهور أنماط من السلوك التلاجتماعي. 


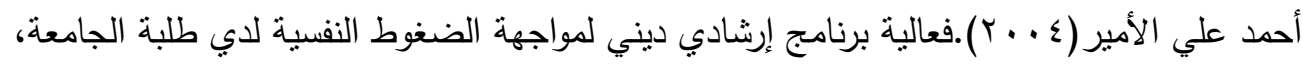

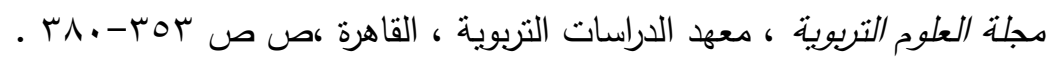

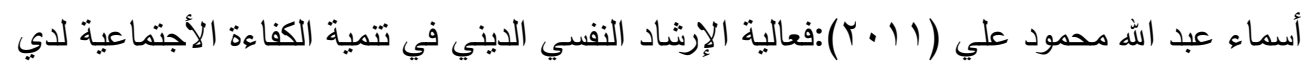

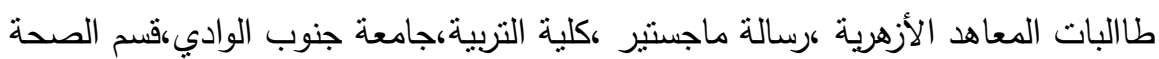
النفسية .

جزاء العصيمى (V . . . r). بعض المشكلات النفسية الثنائعة لدى طلاب مراحل التعلم العام بمدينة

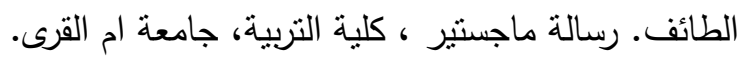

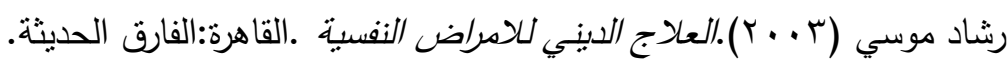

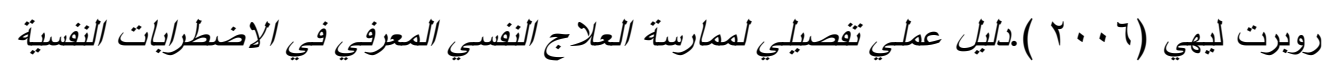
كترجمة جمعة يوسف ومحمد الصبوة.القاهرة:ايتراك للطباعة والنشر والتوزيع.

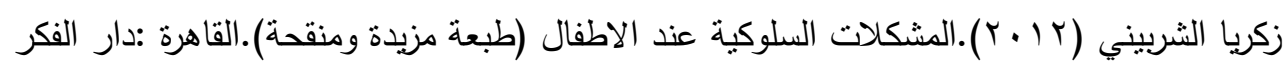
العربي

زكريا الثربيني وآخرون ( . . †)، تتشئة الطفل وسبل الوالدين في معاملة ومواجهة مشكلاته، دار الفكر

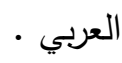

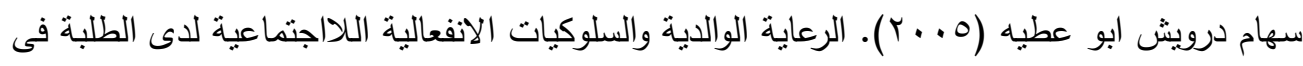

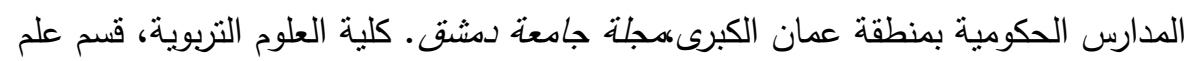

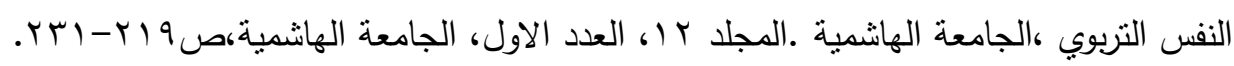

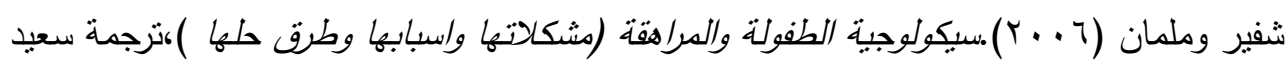
العزة ،دار الثقافة للنشر والتوزيع.

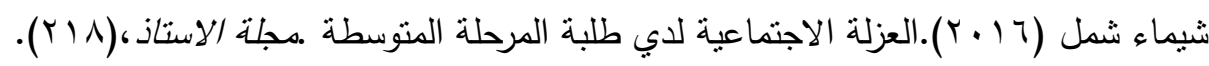

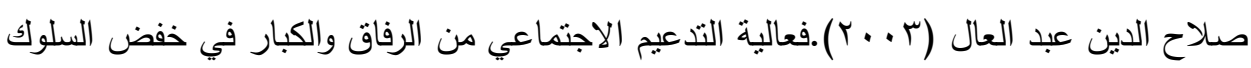

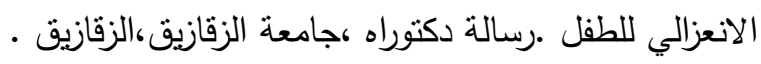

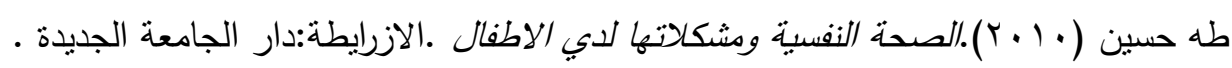

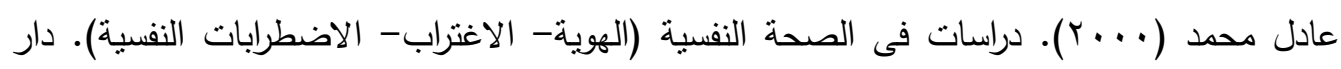
الرشاد.

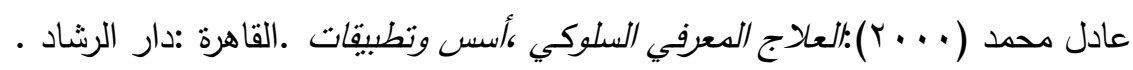


عبد الباسط خضر ( . . ب).مدي فعالية الإرشاد والتدريب علي تتمية المهارات الاجتماعية والمزاوجة

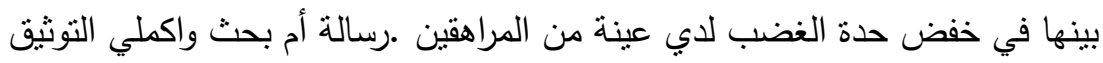

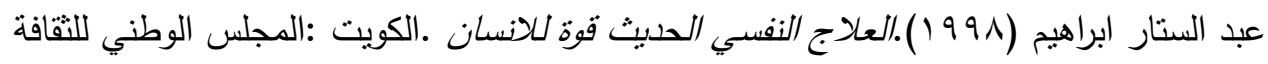
والفنون والاداب.

عبد اللطيف العثمانية (ץ . . r).مستوي المشكلات السلوكية لدي طلبة المرحلة الثانوية في المدارس الحكومية وصعوبة التعامل معها من وجهة نظر المرشدين التربوبين في محافظات شمال

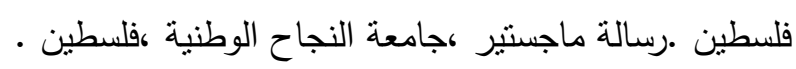

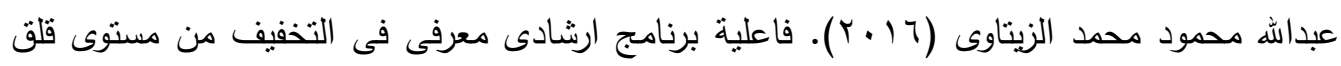
المستقبل وتعديل السلوك اللااجتماعى لاى عينة من المراهقين فى محافظة اربد. مجلة الدنارة

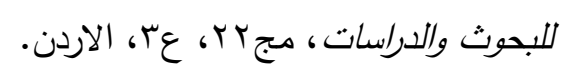

طارق محمود (ع . . ץ). عمل الام وعلاقته ببعض المشكلات النفسية والاجتماعية لأى الابناء. رسالة

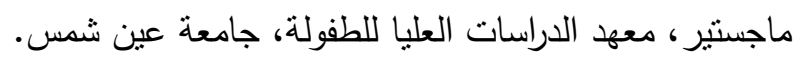

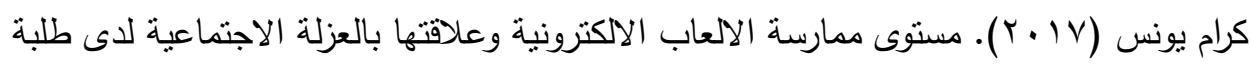

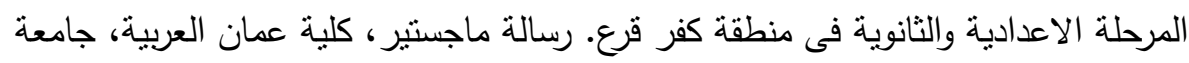

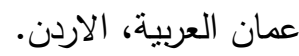

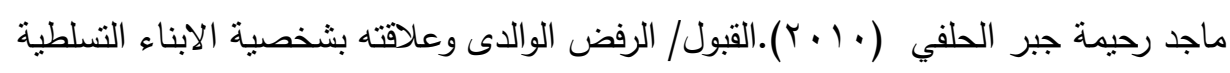

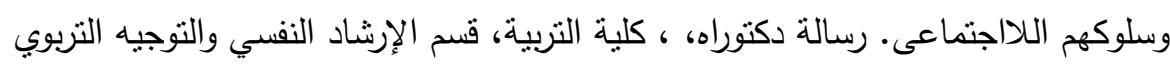
، الجامعة المستتصرية، العراق.

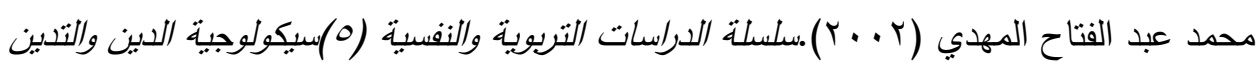

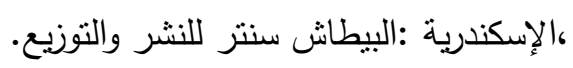
محمد عبد الفتاح المهدي (r . . r):العلاج النفسي في ضوء الإسلام ،سلسلة الدراسات التربوية والنفسية ،الطبعة ( (1)،المنلقي المصري للإببداع والتتمية.

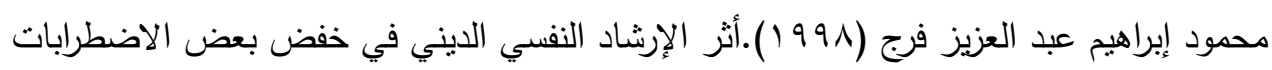

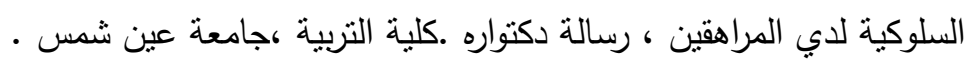

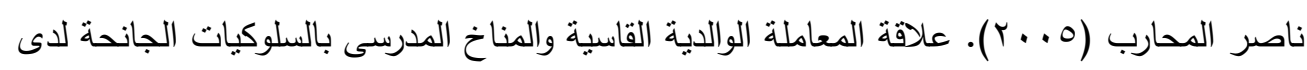
طلاب المدارس المتوسطة والثانوى فى المملكة العربية: علاقة عامة ام علاقات نوعية. دراسات

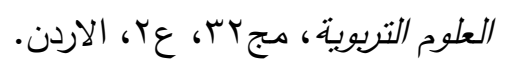


نائل ابو وردة (ـ ( • r). برنامج ارشادى نفسى اسلامى مقترح لتخفيف اعراض الاكتئاب النفسى: دراسة

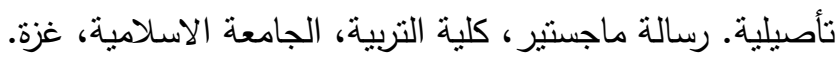

نسيمه داود (999 (19).علاقة الاجتماعية والسلوك اللاإجتماعي المدرسي باساليب التتشئة الوالدية

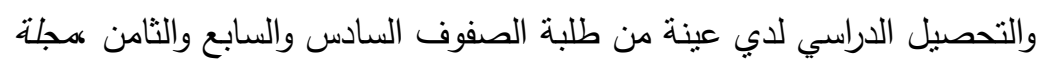

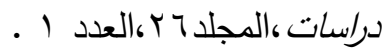

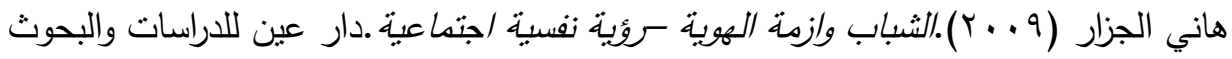
الانسانية والاجتماعية .القاهرة .

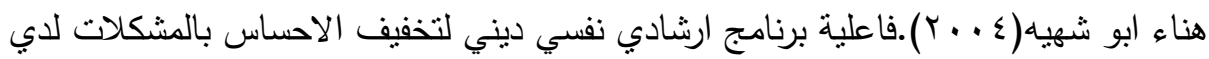

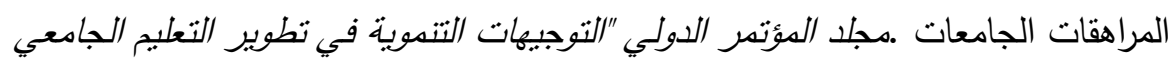

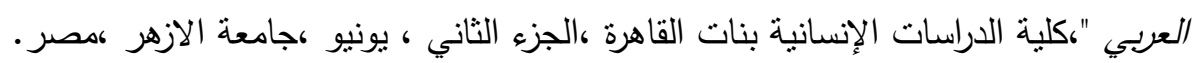

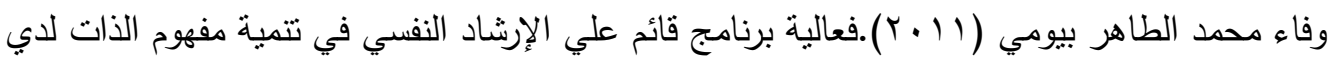

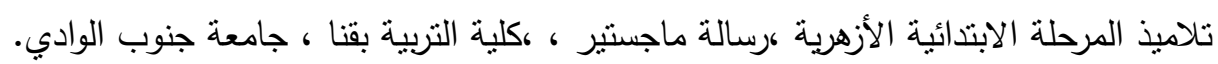

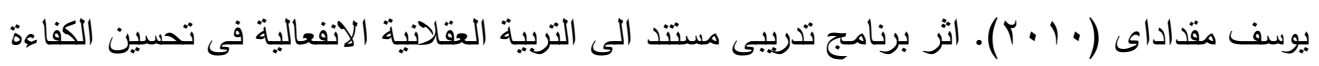

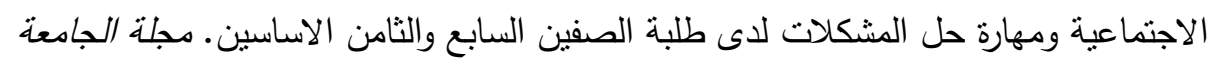

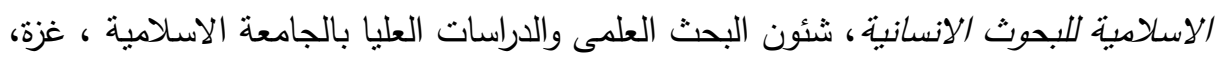

$$
\text { المر اجع الانجليزية العب، فلسطين. }
$$

American psychiatric Association (APA) (2013). Diagnostic and statistical manual of mental disorders. $5^{\text {th }}$ ed, Washington, DC.

Baumesier , f (2011). Emotions and antisocial behavior. The journal of forensic psychiatry \& psychology. 22 (5).

Jamila , M. "Enhancing A classroom social compertence and problem solving curriculum by offcring parcnt Training to Familics of Moderate-to High -Risk Elementary school children", Journal of clinical child and Adolescent psychology,2007,36(4),605-620.

Javeed ,Q (2012). A study of loneliness and self concept male and female adolescences. Indian streams research journal. 2(4).

Mayer,G.R,2001.Antisocial Behavior.Its Causes and prevention within our schools", Eduction And Treatment of children,24(4),414-449.

Minghui ,g (2008). Living about good: Chinese children's ethical discourse. Ed , d degree, Harvard university, united states. 
Murray , p (2009). Teaching about political and social values, international handbooks of education. international handbook of research on teachers and teaching. Volume 21.

Moffitt , T.\& Caspi , A(1998):Anaocation; implications of violence between intimate pertoers for child psychologists.Journal of child psychology and psychiatry $>39,(2)$, p.p.260-381.

$\mathrm{Xu}$, fu (2010). Lying and truth telling in children: from concept to action, child development, 81 (2). 